\title{
Review \\ Artificial Intelligence: A Shifting Paradigm in Cardio-Cerebrovascular Medicine
}

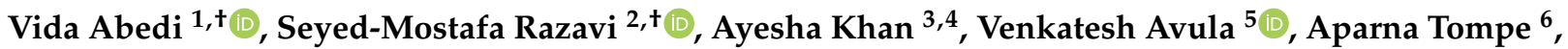 \\ Asma Poursoroush ${ }^{7,8}$, Alireza Vafaei Sadr ${ }^{9}$, Jiang Li $^{5}$ and Ramin Zand ${ }^{3, *}$
}

Citation: Abedi, V.; Razavi, S.-M.; Khan, A.; Avula, V.; Tompe, A.; Poursoroush, A.; Vafaei Sadr, A.; Li, J.; Zand, R. Artificial Intelligence: A Shifting Paradigm in Cardio-Cerebrovascular Medicine. J. Clin. Med. 2021, 10, 5710. https:// doi.org/10.3390/jcm10235710

Academic Editor: Bahi Takkouche

Received: 15 November 2021 Accepted: 2 December 2021 Published: 6 December 2021

Publisher's Note: MDPI stays neutral with regard to jurisdictional claims in published maps and institutional affiliations.

Copyright: (c) 2021 by the authors. Licensee MDPI, Basel, Switzerland. This article is an open access article distributed under the terms and conditions of the Creative Commons Attribution (CC BY) license (https:/ / creativecommons.org/licenses/by/ $4.0 /)$.
1 Department of Public Health Sciences, College of Medicine, The Pennsylvania State University, Hershey, PA 17033, USA; vidaabedi@gmail.com

2 Prime Healthcare, Saint Mary's Regional Medical Center, Reno, NV 89503, USA; razavi.mos@gmail.com

3 Geisinger Neuroscience Institute, Geisinger Health System, Danville, PA 17822, USA; akhan2@geisinger.edu

4 Geisinger Health System, Geisinger Northeast Internal Medicine Residency, Wilkes Barre, PA 18711, USA

5 Department of Molecular and Functional Genomics, Geisinger Health System, Danville, PA 17822, USA; vavula1@geisinger.edu (V.A.); jli@geisinger.edu (J.L.)

6 Geisinger Health System, Transitional Year Residency Program, Bloomsburg, PA 17815, USA; aparnatompe@gmail.com

7 Department of Biomedical Engineering, University of Memphis, Memphis, TN 38152, USA; prsroush@memphis.edu

8 Department of Biomedical Engineering, University of Tennessee Health Science Center, Memphis, TN 38163, USA

9 Départment de Physique Théorique and Center for Astroparticle Physics, University of Geneva, CH-1211 Geneva, Switzerland; vafaei.sadr@gmail.com

* Correspondence: ramin.zand@gmail.com

+ Contributed equally to this work.

Abstract: The future of healthcare is an organic blend of technology, innovation, and human connection. As artificial intelligence (AI) is gradually becoming a go-to technology in healthcare to improve efficiency and outcomes, we must understand our limitations. We should realize that our goal is not only to provide faster and more efficient care, but also to deliver an integrated solution to ensure that the care is fair and not biased to a group of sub-population. In this context, the field of cardio-cerebrovascular diseases, which encompasses a wide range of conditions-from heart failure to stroke - has made some advances to provide assistive tools to care providers. This article aimed to provide an overall thematic review of recent development focusing on various AI applications in cardio-cerebrovascular diseases to identify gaps and potential areas of improvement. If well designed, technological engines have the potential to improve healthcare access and equitability while reducing overall costs, diagnostic errors, and disparity in a system that affects patients and providers and strives for efficiency.

Keywords: healthcare; artificial intelligence; cerebrovascular diseases; cardiovascular diseases; cardio-cerebrovascular diseases; machine learning

\section{Introduction}

Artificial intelligence (AI) focuses on how computers learn from large and complex datasets by mimicking the human thought process. AI has the potential to accelerate the field of precision medicine by helping practitioners to calculate the risk, guide the treatment, predict the outcome, and close the care gap using scalable computational resources and advanced algorithms applied to a growing body of data and knowledge. AI can be specifically designed to improve clinical care and increase efficiency in drug discovery [1]. Carefully designed and implemented electronic health record (EHR)-AI embedded tools and applications can save valuable time and assist practitioners with critical decision-making at the point of care. AI can potentially improve health disparity 
and address implicit bias. Machine learning (ML), an application of AI, provides systems with the ability to learn from data and experiences [2].

Cardio-cerebrovascular diseases, a leading cause of mortality and disability in the United States and worldwide [3,4], have been targeted by big data science and AI applications. Furthermore, with growing vascular risk factors, trends in mortality and complications will be increasing [5]. Many large studies in cardiovascular medicine use AI to provide a promising set of assistive tools to cardiologists and push the boundaries of translational science. Cardiovascular and cerebrovascular diseases share many predictors, pathophysiology processes, among others [6-8]. However, big data and advanced prediction modeling have not been studied in the same way in the cardio and cerebrovascular fields. Our intent in this work was to perform a review of the recent AI-enabled applications developed for cardiovascular and cerebrovascular conditions for different stages of care management (Figure 1).

Stages Where Artificial Intelligence Can Assist in Cardio-cerebrovascular Medicine

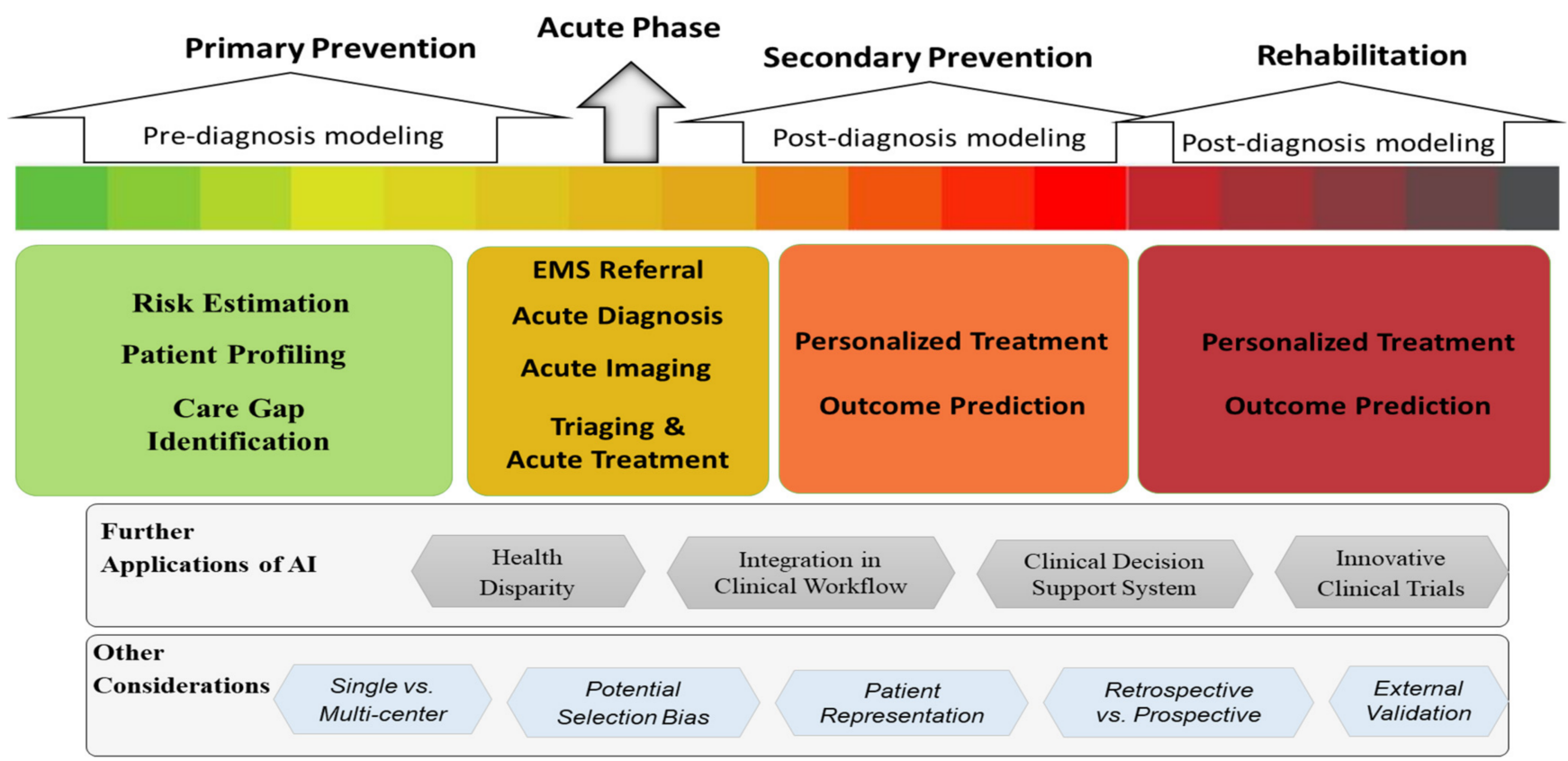

Figure 1. Stages of the care management where artificial intelligence (AI) can add value in cardio and cerebrovascular fields.

\section{Methods}

We conducted a comprehensive literature search to extract original contributions in the various areas of AI application in cardio-cerebrovascular diseases published between 2017-2020. We defined cardiovascular diseases as ischemic heart disease, heart failure, myocardial infarction, and hypertrophic diseases, excluding arrhythmias, infiltrative cardiomyopathies, and genomics. Cerebrovascular diseases were defined as stroke (hemorrhagic/ischemic), thrombosis, and cerebral aneurysmal disorders, excluding genomics. The detailed search criterion is outlined in Figure 2. We examined 256 articles in the field of cardiovascular medicine and included 44 studies in this review article. Similarly, we reviewed 235 studies in cerebrovascular diseases and included 29 studies in this review. We assessed the reporting quality of the studies based on the TRIPOD (transparent reporting of a multivariable prediction model for individual prognosis or diagnosis) statement for including studies in this review [9]. We further divided the studies based on the clinical application; pre-diagnostic, diagnostic/ imaging, and post-diagnostic. Other developing areas of $\mathrm{AI}$ research, such as $\mathrm{AI}$ in clinical trials and subtyping, AI-powered clinical decision 
support systems, as well as application of $\mathrm{AI}$ in reducing health disparity and implicit bias, have also been briefly discussed.

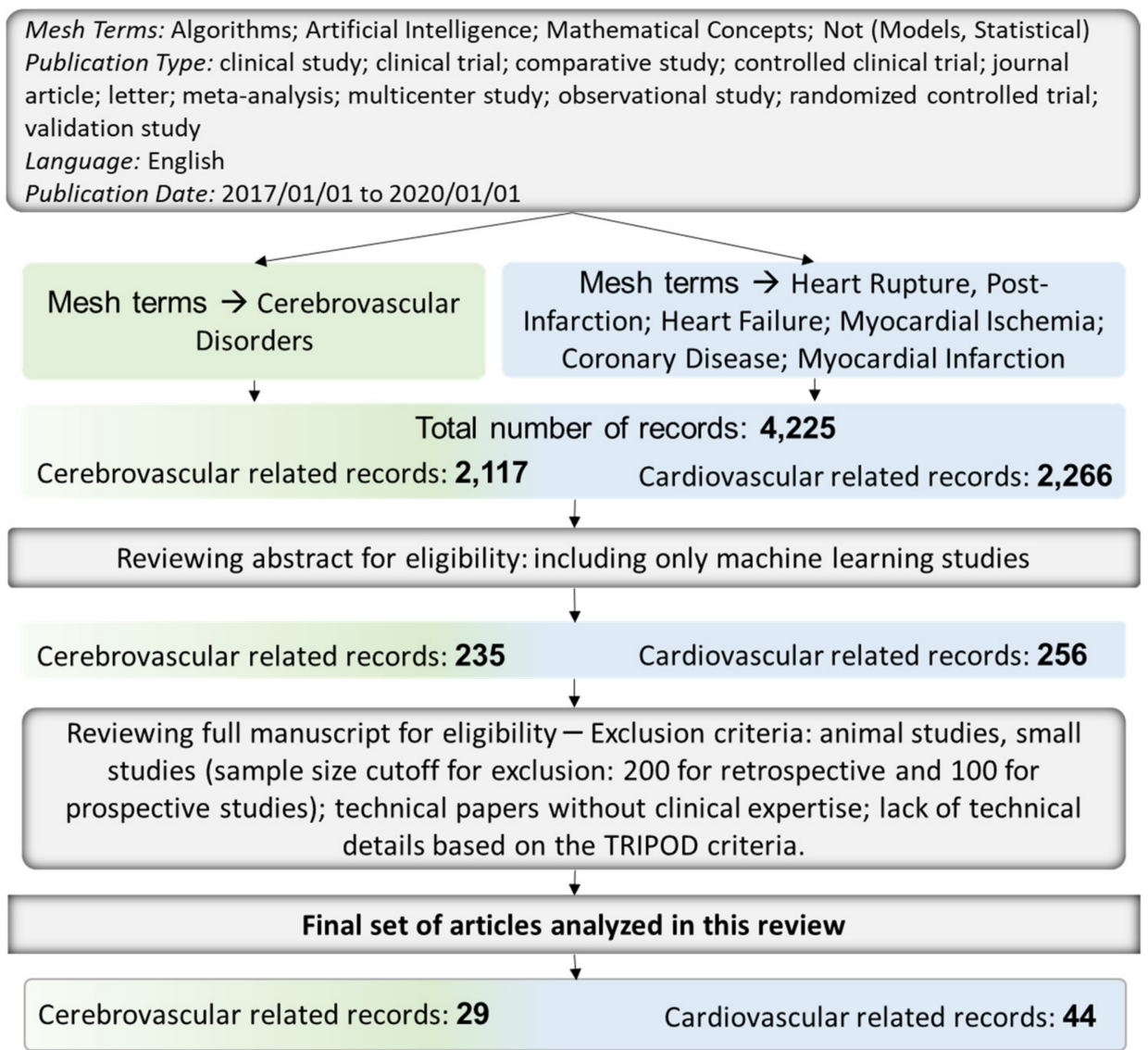

Figure 2. Flowchart for inclusion of studies in the review article.

\section{Results}

A total of 73 cardio-cerebrovascular studies were identified and included in this review. More specifically, 29 studies were cerebrovascular, while 44 studies included cardiovascular diseases (Tables 1 and 2), with the majority of the cerebrovascular study designs being single-center and retrospective. The reviewed studies were divided into the following categories: Risk stratification modeling (11 cardiovascular, 5 cerebrovascular), Diagnostic studies (4 cardiovascular, 5 cerebrovascular), Outcome prediction and prognosis (18 cardiovascular, 6 cerebrovascular), Treatment strategies ( 3 cardiovascular, 2 cerebrovascular), and Diagnostic imaging studies (8 cardiovascular, 10 cerebrovascular). Tables 1 and 2 provide a detailed description of the included studies categorized as mentioned above. The text that follows will further subcategorize the studies to better dissect the various fields of application of AI. The pertinent subsections are also mentioned in the tables to improve readability.

\subsection{Application of AI in Pre-Diagnosis Modeling: Primary Prevention}

(a) Risk Estimation

Risk assessment tools are becoming more salient in the era of precision medicine. EHR and administrative databases in conjunction with advanced applications of AI have been the driving force behind primary prevention strategies for cardiovascular and related conditions (Table 1). Some of the noteworthy applications using ML for risk estimation included an improved prediction of cardiovascular risk factors in patients with no prior risk factors [10], prediction models of long-term risk of MI and cardiac death in asymptomatic 
patients [11], and using ML to identify cardiovascular disease risk factors in patients with no initial indications [12,13]. Researchers also looked at the association of biomarkers such as hemoglobin $\mathrm{A} 1 \mathrm{c}(\mathrm{HbA} 1 \mathrm{c})$ and thyroid-stimulating hormones, and the use of machine learning (support vector machine, SVM) to identify participants who later developed coronary heart disease [14]. Another study utilized AI-enabled tools in imaging to evaluate the prediction of major cardiovascular events in asymptomatic patients [15]. Predicting survival via ML utilizing echocardiography and CT angiogram (CTA) has also been attempted with promising results [16,17]. Four large-scale studies, mainly from Asian countries, have focused on estimating the risk of cerebrovascular disease (Table 2) [18-21]. These studies have sought to estimate the risk of stroke in patients with atrial fibrillation. Cerebrovascular studies on risk stratification are mostly retrospective and suffer from limited diversity and smaller sample sizes compared to cardiovascular studies. For instance, in some cardiovascular studies, existing clinical trials have been leveraged (MESA cohort [22] and EISNER trial [23]) with rich extended longitudinal follow-up data (up to ten years); cerebrovascular studies, on the other hand, have a relatively narrower timeline (up to two years).

\section{(b) Clustering and Patient Profiling Before Event}

Researchers have used ML to group cardiovascular patients based on coronary artery disease (CAD) severity [24], ischemia scoring [25], obstructive disease [26], and coronary stenosis [27]. ML has also been used to discriminate between healthy individuals and patients with impaired functional reserve due to heart failure with preserved ejection fraction (HFpEF) [28]. With regard to cerebrovascular disease, investigators have implemented ML to improve aneurysm detection with time-of-flight MR angiography [29]. Patient clustering has numerous potential benefits for the patients and the health system. Besides cardiovascular and cerebrovascular diseases, patient profiling has been valuable in other complex diseases [30-34].

(c) Care Gap Identification and Personalized Prevention

Identification of care gaps in medical management is an important potential field for ML with high clinical value. This field is not fully developed in either cardio or cerebrovascular diseases and can be a potential new venue for exploration and advanced application of AI for improving the quality of care and resource optimization.

In the period of studies collected for this article, only four studies were identified to concentrate on minimizing the healthcare gap. On the cardiovascular front, ML has been used to develop a risk calculator to aid with the initiation of statin therapy for CAD, which can potentially minimize future cardiovascular events in the affected patients [13]. By reclassifying CTA results, ML has been successful in better predicting existing ischemia and distinguishing that from subclinical coronary stenosis [27]. One cerebrovascular study to use ML for closing the care gap focused on better detection of cerebral aneurysms in MR angiography image data [29]. Karlsson et al. assessed an ML-powered clinical decision support system (CDSS) for stroke prevention in a randomized clinical trial on patients with atrial fibrillation (AF). The study corroborated that the CDSS can increase guideline adherence for anticoagulation therapy among these patients [35].

Personalized prevention is another area with potential clinical value. Thus far, ML has only been utilized to predict obstructive coronary disease on myocardial perfusion imaging as a directive for preventive action at an individual level [26].

\subsection{Application of Computational Algorithms in Diagnosis and Acute Phase Treatment}

(a) Emergency Medical Services (EMS) Proper Referral

Quality of recovery, in both MI and stroke patients, is dependent on the time from symptoms to intervention [36-38]. AI can aid in shortening this time window and improving treatment outcomes. However, there are technological barriers, including access to real-time patient data for model prediction, that make this space complex in terms of its implementation. For instance, in a study by Potter and colleagues, computational algorithms were used for developing an AI-aided system to more promptly identify and 
refer STEMI patients for cardiac catheterization during the EMS encounter [39]. Using this method for "physician-less" cardiac catheterization lab activation was safe and effective in improving treatment delay with sustainable results over time. To this end, investment in this emerging application of AI can help save lives while reducing systemwide cost and physician burnout due to stress that is due to the patient's higher risk for disability and death.

\section{(b) Acute Diagnosis}

ML can be an essential tool to guide physicians in the acute diagnosis of cardio- and cerebrovascular disease. Most ECG recording devices now possess computational abilities to calculate measurements and "read" ECGs in real-time with variable accuracy [40]. With recent advances in computational algorithms, ML has been used to develop advanced diagnostic systems that can make predictions and direct the pre-hospital diagnosis of acute coronary syndrome $[39,41]$.

Timely diagnosis of ischemic and hemorrhagic stroke, while challenging for physicians, is invaluable for the patient. ML has been explored by researchers for stroke screening [42], detection of stroke and large vessel occlusion using CTA imaging [43,44], detection and subtyping of hemorrhagic stroke on CT scans [45-48], and to predict post-stroke mortality $[49,50]$. Researchers have also used ML to aid in the acute diagnosis of TIAs and differentiate them from their mimics [51].

\section{(c) Acute Imaging}

The use of machine learning, especially deep learning in the field of imaging, has grown exponentially in recent years, leading to improved prediction and diagnosis ability. For cardiovascular disease, ML has been used to aid in the diagnosis and classification of acute and subacute coronary stenosis. Researchers have used ECG data to identify patients with chest discomfort who need urgent revascularization [41]. Other investigators have developed algorithms to make similar diagnoses and classification from myocardial perfusion imaging [26], CT angiography [52], and clinical and laboratory data [53] in emergency settings.

The two main imaging modalities for the detection of stroke are CT scans and MRI. In the past four years, many studies have been performed in stroke patients that used ML to detect, quantify and subtype ICH on non-contrast CT [46-48,54] and MRI [55] in the acute phase. Researchers have also used support vector machine (SVM) algorithms to predict the expansion of hematoma in patients with spontaneous ICH [56]. In hemorrhagic stroke, ML has shown to be promising in detecting large vessel occlusion on CTA [44] and also predicting and quantifying the ischemic core [43,57]. In a different study, Fhager and colleagues implemented binary classification on a broadband microwave imaging technique that can potentially detect ICH outside of dedicated stroke centers [45].

Although advances in the application of machine learning for acute imaging had significant progress in both fields, ML has been used more extensively in the quantification of brain biomarkers when compared to markers from cardiovascular imaging. Nonetheless, the field is at the stage of transitioning to prospective trials and effective implementation at the bedside in multiple settings.

\section{(d) Triaging and Acute Treatment}

While diagnosis in cardio-and cerebrovascular fields is one of the first steps after hospital admission, risk stratification during triage can help optimize the available resources and tailor the care management. However, the need for rapid response also requires the tools to interact in real-time with the output from the imaging device and the EHR data. Therefore, the implementation of such tools can be complex and often require coordination at different levels. For instance, the risk of in-hospital cardiac arrest has been predicted using a decision tree [58], while other ML algorithms have been used for risk stratification of chest pain patients using coronary CTA data [52]. These tools, once externally validated and implemented to act in real-time in clinical settings, could help reduce the time for treatment and help save lives. 
Using technologies to improve triaging during the acute phase has been more productive in recent years in the cerebrovascular field. ML has been used for recognition and differentiation of ischemic stroke using clinical data [42] and to predict the 90-day mRS score to aid with thrombectomy [59]. MRI data has been used for the classification of ischemic stroke onset time [60] and segmentation and phenotyping of acute ischemic lesions [55]. Researchers have also used ML to estimate ICH volume on CT scan images [47]. The use of ML in triaging stroke patients has escalated further, and authors have discussed the scope and limitations of an ML-based decision support system framework to aid physicians in urgent settings.

In a real-world environment, initial patient notes can complement pre-event information, if available, for the identification of patients at risk of stroke, and alert the physician to take the guideline-compliant steps to improve the outcome [61]. However, the processing of clinical notes requires advanced natural language processing (NLP) that is carefully tailored for clinical applications. NLP has been mostly applied to reports (such as radiology reports) with promising results [62]; NLP applied to clinical notes can have clinical utility at improving the identification of patients for major vascular events [61].

\subsection{Application of AI in Post-Diagnosis Outcome Prediction and Secondary Prevention}

\section{(a) Personalized Treatment}

Patient subtyping is a central part of personalized patient care and can be a standalone tool to classify patients with similar profiles based on the available information on the patients and their family members.

Finding clusters of stroke patients can be helpful from the medical perspective as it may lead to the discovery of new patterns and more effective ways to manage a specific condition and its complications. Garg et al. [63] developed an automated stroke subtype classification using radiology and progress reports and showed agreement with the manual TOAST (Trial of ORG 10172 in acute stroke treatment) [64] classification. The challenge of the study remains in its validation in an external cohort. Some other studies are attempting to create a CDSS to help physicians classify stroke subtypes based on limited clinical data. Keerthana [65] used Fuzzy C-Means clustering techniques for the segmentation of brain stroke using MRI images. The study lacked technical details, including the number of cases used in model development and testing. Subtyping in the field of cardiovascular medicine is relatively new, with clinical applications that remain relatively sparse $[28,66-70]$. Shah et al. predicted the survival of patients with HFpEF using an unsupervised learning model and demonstrated the benefits of deep phenotyping in these patients [71]. The researchers created an unsupervised learning model across 46 different variables to identify intrinsic structures within patients with HFpEF; they identified three distinct groups. The study needs to be replicated in external HFpEF cohorts to demonstrate generalizability. Zhao et al. applied a constrained non-negative tensor factorization approach to classifying patients with the cardiovascular disease based on their longitudinal EHR data [72]. The latter study is unique as it encompasses data from patients ten years before their development of heart disease with the observation of emerging phenotypes of 12,380 cardiovascular diseases. In another study, Ahmad et al. [73] analyzed data from 1619 participants in the HF-ACTION (Heart Failure: A Controlled Trial Investigating Outcomes of Exercise Training) to identify the subtypes of chronic heart failure. The study design excluded patients with incomplete data, thus limiting the true value of the predicting models for clinical applications. Nonetheless, four subtypes were identified, and each patient in the corresponding subtype responded distinctively to exercise therapy. In another study, Schulam et al. [74] used Limestone, a non-negative tensor factorization algorithm, to identify multiple candidate phenotypes of heart failure. Their clinical evaluation results showed the potential ability of Limestone to produce the phenotypes that can identify disease subtypes with potential clinical utility. Panahiazar et al. [75] used clustering techniques to investigate the heart failure patients' response to therapy. The authors used K-means and hierarchical clustering to group heart failure patients that responded to medication. 
The similarity assessment of a new patient with each identified cluster could lead to the determination of an appropriate medication plan. The major limitation in these studies remains selection bias, given that in many cases, patients with a poor data footprint are excluded from modeling. However, overall, these examples demonstrated the potential of ML-enabled methods based on patient similarity as assistive tools.

\section{(b) Outcome Prediction}

Prediction of outcome after diagnosis was the most extensively investigated application of ML among the categories included in this literature review. Here, the outcomes of interest included, but were not limited to, disease severity, survival, mortality, length of hospitalization, rehospitalization, and recurrence. In patients with confirmed coronary artery disease (CAD), clinical and laboratory data have been used in addition to CTA [17,76], and angiogram [77] to predict cardiovascular events or death with promising results. In one study by Johnson and colleagues, ML algorithms proved superior to CAD reporting and data system (CAD-RADS) scoring in predicting future cardiovascular events and mortality in patients with positive CTA results [17]. In another study, the random forest-based model was shown to better identify patients at risk of 30-day congestive heart failure rehospitalization and 180-day cardiovascular mortality following a percutaneous coronary intervention, compared to conventional methods [78]. Other studies have explored the application of ML in patients admitted for acute coronary syndrome to predict in-hospital mortality [79], 30-day mortality [80], and long-term survival [81-84]. Duane et al. have proposed a deep learning model using static and dynamic features in 2930 patients with acute coronary syndrome to predict major adverse events in the future [85]. A major study from Sweden used 39 survival predictor variables in 51,943 patients to develop various ML models that could accurately predict two-year survival after the first MI event [82]. At the same time, Pieszo et al. used laboratory values in MI patients to predict long-term mortality, while Kwon and colleagues combined laboratory data with patient demographics to make similar predictions $[83,84]$.

Heart failure is yet another area where ML has shown promising results in the prediction of outcomes [86,87]. In the study published by Kwon et al., machine learning algorithms were able to predict in-hospital and long-term mortality following acute heart failure more effectively than conventional scoring systems [88]. Survival in patients with pulmonary hypertension has also been predicted using ML [89]. Distinguishing between short-term vs. long-term mortality is equally beneficial for the patients and healthcare system as it can help with resource optimization as well as more personalized care [50].

Ischemic and hemorrhagic stroke has been the main focus of cerebrovascular studies with regard to secondary prevention and functional outcome as well as mortality prediction. Researchers used deep learning on acute ischemic stroke imaging features to predict lesion volume [90]. Two different teams of scientists have used ML algorithms to predict three-month functional outcomes following ischemic stroke [91,92]. ML has also been utilized to predict 90-day readmission [93] and one-year recurrence in patients with ischemic stroke [94]. In patients undergoing endovascular treatment for ischemic stroke, ML algorithms did not improve outcome prediction when compared to logistic regression [95]. In hemorrhagic intracranial events, ML has been successful in predicting hematoma expansion [56] and delayed ischemia [96].

As such, there has been an increasing number of successful applications of AI in predicting outcomes in cardiovascular and cerebrovascular diseases, raising the question of when these improvements can be evaluated for clinical utility and generalizability to reach patients' bedsides. In this context, the functional outcome in stroke patients is primarily measured by the modified Rankin Scale (mRS) score [97], while the New York Heart Association (NYHA) classification is used to categorize heart failure patients [98]. Using these scores as features in the machine learning models can be important for training the models. However, the main limiting factor remains the lack of proper reporting of functional classes and the level of missingness in these measurements across the different healthcare systems. Incorporating functional outcomes in a structured form in EHR data to 
enable easier integration of these measures in machine learning models is an important first step. Better, more consistent, and standardized reporting of functional class scores will ultimately lead to better model predictions.

\subsection{Application of AI in Rehabilitation}

(a) Personalized Treatment

Studies on the use of ML in assisting with rehabilitation have been limited. In heart failure patients, ML helped investigators to classify heart failure patients based on clinical presentation and improve treatment response by directing personalized therapies [99]. In the only cerebrovascular study, researchers used ML to predict activities of daily living in post-stroke patients to better optimize clinical care [100]. Personalized treatment for tertiary prevention is an area with great potential for the application of AI. Rehabilitation in both cardio and cerebrovascular patients has a major financial burden on healthcare systems [101,102]. Innovative use of ML in this field can lead to improved resource optimization and personalized patient experience [103].

\section{(b) Outcome Prediction}

Outcome prediction using ML during rehabilitation in cardiovascular studies has been mainly focused on cardiac resynchronization therapy outcomes in patients with heart failure. Researchers have used ML to predict patient response to cardiac resynchronization [104], outcome [105], and mortality [106]. ML has also been used to distinguish different heart failure phenotypes [86] and predict survival with the aid of echocardiography data [16]. In the only cerebrovascular study that we were able to identify, researchers used ML to predict activities of daily living in post-stroke patients to better optimize clinical care [100]. This field has great potential for future studies and trials to improve the recovery and quality of life of patients.

Table 1. Cardiovascular studies using artificial intelligence.

\begin{tabular}{|c|c|c|c|}
\hline Ref., Year-Category ** & Study Details & $\begin{array}{l}\text { Sample } \\
\text { Size }\end{array}$ & Algorithms \\
\hline \multicolumn{4}{|c|}{ AI and Risk Stratification Modeling } \\
\hline$[10], 2017-1 \mathrm{a}$ & $\begin{array}{c}\text { Location: United Kingdom } \\
\text { Aim: Predicting the first CVD event over 10-years and comparing } \\
\text { that with the American College of Cardiology guidelines. } \\
\text { Variables: Routine clinical data from family practices } \\
\text { Strengths: Prospective; large sample size } \\
\text { Limitations: Unbalanced dataset } \\
\text { Findings: Highest achieving algorithm was NN: AUC 0.76, } \\
\text { predicted } 4998 / 7404 \text { cases (sensitivity } 67.5 \%, \text { PPV } 18.4 \% \text { ) and } \\
53,458 / 75,585 \text { non-cases (specificity } 70.7 \%, \text { NPV } 95.7 \% \text { ), correctly } \\
\text { predicting } 7.6 \% \text { more patients than the established algorithm }\end{array}$ & 378,256 & RF, LR, GBM, NN \\
\hline
\end{tabular}


Table 1. Cont.

Ref., Year-Category ** $\begin{gathered}\text { Study Details } \\ \text { Location: United States } \\ \text { Size }\end{gathered}$
Aim: Predict six cardiovascular outcomes in comparison to
standard risk scores.
Variables: 735 variables from imaging and non-invasive tests,
questionnaires, and biomarker panels
Strengths: Prospective; included participants from the MESA
(Multi-Ethnic Study of Atherosclerosis) [22]; 12-year follow-up;
four ethnicities
Limitations: Potential cause for biases due to imputation procedure
Findings: Age was the most important predictor for all-cause
mortality. Fasting glucose levels and carotid ultrasonography
measures were important predictors of stroke. CAC was the most
important predictor of coronary heart disease and all
atherosclerotic cardiovascular disease combined outcomes. Left
ventricular structure and function and cardiac troponin-T were
among the top predictors for incident heart failure. Creatinine, age,
and ankle-brachial index were among the top predictors of AF.
TNF- $\alpha$ and IL-2 soluble receptors and NT-proBNP levels were
important across all outcomes.
Notable facts: ML in conjunction with deep phenotyping improves
prediction accuracy in cardiovascular event prediction in an
initially asymptomatic population.

\section{Location: United States}

Aim: Predicting of long-term risk of MI and cardiac death in asymptomatic subjects by integrating clinical parameters with CAC, and automated EAT quantification.

Variables: Clinical co-variates, lipid panel, risk factors, CAC, aortic calcium, and automated EAT measures

Strengths: Prospective; subjects from EISNER trial [23]; 14.5 years follow-up

[11], 2019-1a, 1b Limitations: Unbalanced data

Findings: AUC 0.82; Subjects with a higher ML score had high hazard of suffering events (HR: 10.38, $p<0.001$ ); the relationships persisted in multivariable analysis including ASCVD-risk and CAC measures (HR: 2.94, $p=0.005$ ). Age, ASCVD-risk, and CAC were prognostically important for both genders.

Notable facts: ML used to integrate clinical and quantitative imaging-based variables significantly improves prediction of MI and cardiac death.

\section{Location: China}

Aim: Identifying the association between the clinical reference range of serum $\mathrm{HbA1c}$ and $\mathrm{TSH}$, and the risk of CAD in non-diabetic and euthyroid patients.

Variables: $\mathrm{HbA1c}$ and TSH levels Strengths: Prospective; 10-year follow-up Limitations: Small sample size 
Table 1. Cont.

\begin{tabular}{|c|c|c|c|}
\hline Ref., Year-Category ** & Study Details & $\begin{array}{l}\text { Sample } \\
\text { Size }\end{array}$ & Algorithms \\
\hline [107], 2018-1a & $\begin{array}{c}\text { Location: Lebanon } \\
\text { Aim: Comparing ANN-based prediction models to the other risk } \\
\text { models being used in practice (the Diamond-Forrester and the } \\
\text { Morise models). } \\
\text { Variables: Imaging-based stress test measures } \\
\text { Strengths: Prospective } \\
\text { Limitations: Small sample size } \\
\text { Findings: Compared to other models, the ANN model had higher } \\
\text { discriminatory power (DP) (1.61) for predicting ischemia, } 98 \% \\
\text { negative predictive value, } 91 \% \text { sensitivity, } 65 \% \text { specificity, } 26 \% \\
\text { positive predictive value, and a potential } 59 \% \text { reduction of } \\
\text { non-invasive imaging. }\end{array}$ & 486 & ANN \\
\hline [28], 2018-1b, 3a & $\begin{array}{c}\text { Location: United Kingdom, Italy, Norway } \\
\text { Aim: Discriminating between healthy and HFpEF subjects with } \\
\text { impaired functional reserve and identifying new descriptors to } \\
\text { better characterize HFpEF syndrome using basal myocardial } \\
\text { long-axis velocity patterns at rest and exercise. } \\
\text { Variables: Left ventricular long-axis myocardial velocity patterns } \\
\text { Strengths: Prospective, 6-60 months survival analysis } \\
\text { Limitations: Confounding effects (age, gender) not studied, small } \\
\text { sample size } \\
\text { Findings: ML-diagnostic zones differed for age, body mass index, } \\
\text { six-minute walk distance, B-type natriuretic peptide, and left } \\
\text { ventricular mass index. Correlation with diagnosis was 72.6\%; ML } \\
\text { identified } 6 \% \text { of healthy controls as HFpEF. Blinded reinterpretation } \\
\text { of imaging from subjects with discordant clinical and ML diagnoses } \\
\text { revealed abnormalities not included in diagnostic criteria. }\end{array}$ & 156 & Clustering \\
\hline$[71], 2015-1 b, 3 a$ & $\begin{array}{c}\text { Location: United States } \\
\text { Aim: Identify phenotypically distinct HFpEF categories. } \\
\text { Variables: Clinical, laboratory, ECG, and echocardiographic } \\
\text { phenotyping } \\
\text { (phenomapping) } \\
\text { Strengths: Prospective } \\
\text { Findings: Phenomapping classified study participants into three } \\
\text { risk-stratified groups. } \\
\text { Notable facts: A novel classification of HFpEF using } \\
\text { phenomapping that can define therapeutically homogeneous } \\
\text { patient subclasses. }\end{array}$ & 397 & Clustering \\
\hline$[16], 2019-1 \mathrm{a}, 3 \mathrm{a}, 4 \mathrm{~b}$ & $\begin{array}{c}\text { Location: United States } \\
\text { Aim: Predicting survival after echocardiography. } \\
\text { Variables: } 90 \text { cardiovascular-relevant ICD-10 codes, age, sex, height, } \\
\text { weight, heart rate, blood pressures, LDL, HDL, smoking, } \\
\text { physician-reported EF, } 57 \text { echocardiographic measurements } \\
\text { Strengths: Large sample size } \\
\text { Limitations: Retrospective, model derivation from EHR data } \\
\text { missing important variables } \\
\text { Findings: Overall AUC > 0.82 over common clinical risk scores. RF } \\
\text { outperformed LR. RF including all echocardiographic } \\
\text { measurements yielded the highest prediction accuracy. Ten } \\
\text { variables needed to achieve } 96 \% \text { maximum prediction accuracy, six } \\
\text { from echocardiography. }\end{array}$ & 171,510 & $\mathrm{RF}$ \\
\hline
\end{tabular}


Table 1. Cont.

\begin{tabular}{|c|c|c|c|}
\hline Ref., Year-Category ** & Study Details & $\begin{array}{l}\text { Sample } \\
\text { Size }\end{array}$ & Algorithms \\
\hline$[17], 2019-3 a, 3 b$ & $\begin{array}{l}\text { Location: United States } \\
\text { Aim: Using ML to develop a model of vessel features to } \\
\text { discriminate between patients with and without subsequent death } \\
\text { or cardiovascular events and comparing to CAD-RADS. } \\
\text { Variables: Four CTA features for each of the sixteen coronary } \\
\text { segments } \\
\text { Strengths: Comparing four different ML methods } \\
\text { Limitations: Low MI incidence leading to possible misclassification } \\
\text { bias } \\
\text { Findings: ML all-cause mortality AUC }=0.77 \text {; ML CAD deaths } \\
\text { AUC = 0.85. For starting statin therapy (NNT = 45), use of ML score } \\
\text { ensures 93\% of patients with events will be administered the drug; } \\
\text { compared to } 69 \% \text { with CAD-RADS. } \\
\text { Notable facts: Compared to CAD-RADS, ML better discriminated } \\
\text { patients who subsequently experienced an adverse event from } \\
\text { those who did not. }\end{array}$ & $6892 \mathrm{~b}$ & $\begin{array}{l}\text { Best models: } \\
\text { rap-aggregated DTE, } \\
\text { KNN, }\end{array}$ \\
\hline$[13], 2018-1 \mathrm{a}, 1 \mathrm{c}$ & $\begin{array}{l}\text { Location: United States } \\
\text { Aim: Developing a risk calculator for CAD incidence to aid } \\
\text { initiation of statin therapy. } \\
\text { Variables: Same as ACC/AHA risk calculator } \\
\text { Strengths: Model training by 13-year follow-up data from MESA } \\
\text { cohort [22] and validation by FLEMENGHO cohort [108] } \\
\text { Limitations: Retrospective } \\
\text { Findings: ML Risk Calculator recommended only } 11.4 \% \text { to take } \\
\text { statin, and only 14.4\% of “Hard CVD” events occurred in those not } \\
\text { recommended statin, resulting in sensitivity 0.86, specificity } 0.95 \text {, } \\
\text { and AUC 0.92. } \\
\text { Notable facts: ML Risk Calculator outperformed the ACC / AHA } \\
\text { Risk Calculator by recommending less drug therapy yet missing } \\
\text { fewer events. }\end{array}$ & 10,291 & SVM \\
\hline [109], 2019-1a, 1b & $\begin{array}{c}\text { Location: Iran } \\
\text { Aim: Compare ANN and SVM algorithms for predicting CAD. } \\
\text { Variables: } 25 \text { variables affecting CAD including laboratory values } \\
\text { Strengths: Data collected from three hospitals } \\
\text { Limitations: Retrospective; no detail provided regarding } \\
\text { missingness, or lack thereof } \\
\text { Findings: SVM model had higher AUC, higher sensitivity, higher } \\
\text { Hosmer-Lemeshow test's result and lower MAPE compared to } \\
\text { ANN. Variables affecting CAD yielded better goodness of fit in } \\
\text { SVM model and provided more accurate result than ANN. }\end{array}$ & 1324 & ANN, SVM \\
\hline
\end{tabular}


Table 1. Cont.

\begin{tabular}{|c|c|c|c|}
\hline Ref., Year-Category ** & Study Details & $\begin{array}{l}\text { Sample } \\
\text { Size }\end{array}$ & Algorithms \\
\hline \multicolumn{4}{|c|}{ AI-enabled Diagnostic Studies } \\
\hline [76], 2016-3b & $\begin{array}{l}\text { Location: Multi-national } \\
\text { Aim: Predicting five-year all-cause mortality in patients } \\
\text { undergoing CCTA and comparing to existing prediction algorithms. } \\
\text { Variables: } 25 \text { clinical and } 44 \text { CCTA parameters, SSS, SIS, DI, number } \\
\text { of segments with non-calcified, mixed or calcified plaques, age, sex, } \\
\text { gender, standard cardiovascular risk factors, and FRS } \\
\text { Strengths: Data from CONFIRM registry [110]; large sample size } \\
\text { Limitations: Selection bias; only LogitBoost was evaluated for } \\
\text { efficacy. } \\
\text { Findings: ML exhibited a higher area-under-curve compared with } \\
\text { the FRS or CCTA severity scores alone (SSS, SIS, DI) for predicting } \\
\text { all-cause mortality (ML: } 0.79 \text { vs. FRS: } 0.61, \text { SSS: } 0.64, \text { SIS: } 0.64, \text { DI: } \\
\quad 0.62 ; p<0.001 \text { ). } \\
\text { Notable facts: ML combining clinical and CCTA data was found to } \\
\text { predict five-year all-cause mortality significantly better than } \\
\text { existing clinical or CCTA metrics alone. }\end{array}$ & 10,030 & LogitBoost \\
\hline
\end{tabular}

\section{Location: Korea}

Aim: Developing an angiography-based supervised ML algorithm with five-fold cross-validation to classify coronary lesions based on fractional flow reserve ( $\leq 0.80$ vs. $>0.80)$.

Variables: 24 computed angiographic features based on the diameter plot and four clinical features (age, sex, body surface area, and involve segment)

Strengths: Randomized controlled trial; external validation in 79 patients

[77], 2019—3a, 3b Limitations: Data, analytic methods, and study materials not available to other researchers; model limited to left main disease, side branch, and diffuse and tandem lesions

Findings: ML model predicted fractional flow reserve $\leq 0.80$ with overall diagnostic accuracy of 78\% (AUC $=0.84)$. Using 12 main angiography features, the ML predicted fractional flow reserve $\leq$ 0.80 in the test set with sensitivity of $84 \%$, specificity of $80 \%$, and overall accuracy of $82 \%$ (AUC $=0.87$ ). The averaged diagnostic accuracy in bootstrap replicates was $81 \%(\mathrm{AUC}=0.87)$. External validation showed accuracy of $85 \%$ (AUC $=0.87$ ).

\section{Location: Canada}

Aim: Automating the diagnosis of STEMI at the time of first contact with healthcare system and pre-hospital CCL activation.

$$
\text { Variables: ECG reading data }
$$

[39], 2017-2a, 2b Limitations: Retrospective analysis of real-time automated diagnosis; only ECG data used; small sample size without a significant effect on treatment delay. 
Table 1. Cont.

\begin{tabular}{|c|c|c|c|}
\hline Ref., Year-Category ** & Study Details & $\begin{array}{l}\text { Sample } \\
\text { Size }\end{array}$ & Algorithms \\
\hline$[41], 2019-2 b, 2 c, 2 e$ & $\begin{array}{l}\text { Location: Japan } \\
\text { Aim: Making an AI prediction model for the need for urgent } \\
\text { revascularization from 12-lead ECG in patients presenting with } \\
\text { chest pain in the ER. } \\
\text { Variables: ECG reading data } \\
\text { Limitations: Retrospective; only ECG data used, small sample size } \\
\text { Findings: Predictive value of the c-statistics } 0.88 \text { (95\% CI 0.84-0.93) } \\
\text { for detecting patients who required urgent revascularization. }\end{array}$ & 362 & LSTM \\
\hline \multicolumn{4}{|c|}{ AI in Outcome Prediction/Prognosis } \\
\hline [89], 2017-3b & $\begin{array}{c}\text { Location: United Kingdom } \\
\text { Aim: Predicting patient survival in pulmonary hypertension using } \\
\text { 3D patterns of systolic cardiac motion. } \\
\text { Variables: Conventional imaging; hemodynamic, functional, and } \\
\text { clinical markers; 3D motion pattern of right ventricle } \\
\text { Strengths: Prospective } \\
\text { Limitations: Limited patient selection including non-congenital } \\
\text { cases of PH. Model trained to measure excursion rather than } \\
\text { contractility. } \\
\text { Findings: Survival prediction AUC 0.73; difference in median } \\
\text { survival time between high- and low-risk groups was } 13.8 \text { years. }\end{array}$ & 256 & $\begin{array}{l}\text { Supervised ML using } \\
\text { nested multivariable risk } \\
\text { prediction }\end{array}$ \\
\hline [111], 2019-3a & $\begin{array}{c}\text { Location: United States } \\
\text { Aim: Testing generalizability and precision in imaging biomarker } \\
\text { analysis by comparing scan:rescan data. } \\
\text { Variables: MR-measured left ventricular chamber volumes, mass, } \\
\text { and ejection fraction } \\
\text { Strengths: Prospective } \\
\text { Limitations: Data from five institutions, but scans performed at the } \\
\text { same institution; one-week interval between scans limited the } \\
\text { ability to assess long-term changes } \\
\text { Findings: Expert, trained junior, and automated scan:rescan } \\
\text { precision were similar (coefficient of variation } 6.1 \text { vs. } 8.8 \text { ). } \\
\text { Automated analysis was } 186 \times \text { faster than humans. }\end{array}$ & 110 & $\mathrm{CNN}$ \\
\hline
\end{tabular}

$$
\text { Location: Sweden }
$$

Aim: Predicting two-year survival vs. non-survival after first MI.

Variables: 39 survival predictors

Strengths: Large sample size

Limitations: Retrospective

[82], 2017-3b

Findings: SVM had the highest performance (AUC $=0.845, \mathrm{PPV}=$ not significantly higher than LR or RF. Models converged to the point of algorithm indifference with increased sample size and predictors.

\section{Location: Sweden}

Aim: Using mixture of supervised and unsupervised approach to predict outcome and identify distinct phenotypes of heart failure. Variables: Demographic, clinical, laboratory, and medication data Strengths: Large sample size

Limitations: Retrospective

[86], 2018-3b, 4b
Findings: RF demonstrated excellent calibration and discrimination for survival $(C$-statistic $=0.83)$ whereas LVEF did not $(C$-statistic $=$ 0.52). Cluster analysis using the eight highest predictive variables identified four clinically relevant subgroups of HF with marked differences in one-year survival. 
Table 1. Cont.

\begin{tabular}{|c|c|c|c|}
\hline Ref., Year-Category ** & Study Details & $\begin{array}{l}\text { Sample } \\
\text { Size }\end{array}$ & Algorithms \\
\hline [79], 2017-3b & $\begin{array}{l}\text { Location: United States } \\
\text { Aim: Modeling all-cause in-hospital mortality in women admitted } \\
\text { with STEMI. } \\
\text { Variables: } 11 \text { variables for LR; } 32 \text { variables for full RF model; } 17 \\
\text { variables for reduced RF model } \\
\text { Strengths: Model validation using external cohort of } 13,361 \text { patients } \\
\text { Limitations: Retrospective; class imbalance (in-hospital mortality in } \\
11 \% \text { of patients) } \\
\text { Findings: Internal validation C-index was } 0.84,0.81 \text {, and } 0.80 \text { for } \\
\text { the LR, full, and reduced RF models, respectively. External } \\
\text { validation C-index was } 0.84,0.85 \text {, and } 0.81 \text { for year } 2011 \text {, and } 0.82 \text {, } \\
\text { 0.81, and } 0.81 \text { for the year } 2013 \text { for the LR, full, and reduced RF } \\
\text { models, respectively. } \\
\text { Notable facts: RF was comparable to LR in predicting in-hospital } \\
\text { mortality in women with STEMI. }\end{array}$ & 12,047 & LR and RF \\
\hline$[84], 2019-3 b$ & $\begin{array}{l}\text { Location: Korea } \\
\text { Aim: DL-based risk stratifying mortality of patients with acute MI. } \\
\text { Variables: Initial demographic and laboratory data } \\
\text { Strengths: Large sample size; data from the Korean working group } \\
\text { of myocardial infarction registry (network of } 59 \text { hospitals) } \\
\text { Limitations: Retrospective } \\
\text { Findings: AUC for STEMI }=0.905 \text {. AUC for NSTEMI = 0.870. DL } \\
\text { predicted 30.9\% of patients more accurately than conventional } \\
\text { scores. During the six-month follow-up, the DL-defined high-risk } \\
\text { group had a significantly higher mortality rate than the low-risk } \\
\text { group ( } 17.1 \% \text { vs. } 0.5 \%) .\end{array}$ & 22,875 & $\mathrm{DL}, \mathrm{LR}, \mathrm{RF}$ \\
\hline$[58], 2019-2 d, 3 b$ & $\begin{array}{c}\text { Location: China } \\
\text { Aim: Identify in-hospital cardiac arrest in hospitalized patients } \\
\text { with acute coronary syndrome. } \\
\text { Variables: Seven explanatory variables: VitalPAC Early Warning } \\
\text { Score (ViEWS), fatal arrhythmia, Killip class, cardiac troponin I, } \\
\text { blood urea nitrogen, age, and diabetes } \\
\text { Limitations: Possibility of selection bias } \\
\text { Findings: Sensitivity = 0.762; Specificity = 0.882; AUC = 0.844; a } \\
\text { 10-fold cross-validated risk estimate = 0.198; optimism-corrected } \\
\text { AUC = 0.823. } \\
\text { Notable facts: The developed DT model may provide healthcare } \\
\text { workers with a practical bedside tool and could positively impact } \\
\text { decision-making in deteriorating patients with ACS. }\end{array}$ & 656 & DT \\
\hline$[78], 2019-3 b$ & $\begin{array}{l}\text { Location: United States } \\
\text { Aim: Identify patients at risk of death or CHF rehospitalization } \\
\text { after PCI. } \\
\text { Variables: } 52 \text { features at admission to predict in-hospital mortality; } \\
\quad 358 \text { features at discharge to predict CHF readmission } \\
\text { Strengths: Large sample size } \\
\text { Limitations: Retrospective; high missingness level in certain } \\
\text { features causing high data sparsity } \\
\text { Findings: RF prediction of in-hospital mortality AUC }=0.925 . \mathrm{RF} \\
\text { outperformed LR for predicting 30-day CHF readmission (AUC: } \\
0.90 \text { vs. } 0.85 \text { ) and 180-day cardiovascular death (AUC: } 0.88 \text { vs. } 0.81 \text { ). }\end{array}$ & 11,709 & $\mathrm{RF}$ \\
\hline
\end{tabular}


Table 1. Cont.

\begin{tabular}{|c|c|c|c|}
\hline Ref., Year-Category ** & Study Details & $\begin{array}{l}\text { Sample } \\
\text { Size }\end{array}$ & Algorithms \\
\hline [88], 2019-3b & $\begin{array}{l}\text { Location: Korea } \\
\text { Aim: Developing and validating a deep-learning-based AI } \\
\text { algorithm for predicting mortality of acute HF. } \\
\text { Variables: Demographics, treatment and medication, laboratory, } \\
\text { ECG and echocardiography findings, final diagnosis, clinical } \\
\text { outcome during hospital stay, and 12-month prognosis } \\
\text { Strengths: Multi-center study; large sample size } \\
\text { Limitations: Retrospective } \\
\text { Findings: AUC of the DL was 0.880 for predicting in-hospital } \\
\text { mortality, which outperformed other machine learning models. For } \\
\text { predicting 12- and 36-month endpoints, DL had an AUC of 0.782 } \\
\text { and 0.813, respectively. During the 36-month follow-up, the } \\
\text { high-risk group, defined by the DL, had a significantly higher } \\
\text { mortality rate than the low-risk group. }\end{array}$ & 6924 & DNN, RF, LR, SVM, BN \\
\hline
\end{tabular}

\section{Location: Korea}

Aim: Using ML to predict ACS requiring revascularization in

patients presenting with early-stage angina-like symptoms.

Variables: 20 features relevant to ACS

Strengths: Large sample size

[53], 2019-2c, 2d

Limitations: Retrospective; inaccuracy in checking the vulnerable

Findings: $\mathrm{AUC}=0.860$ for the prediction of $\mathrm{ACS}$ requiring

revascularization. A reliable prediction of $2.60 \%$ of non-ACS

patients was made with a specificity of 1.0 to only receive medical therapy.

\section{Location: United States}

Aim: Using a ML algorithm to predict mortality in HF patients.

Variables: Eight variables: diastolic blood pressure, creatinine,

blood urea nitrogen, hemoglobin, white blood cell count, platelets, albumin, and red blood cell distribution width

Strengths: Large sample size

[87], 2019-3b

Limitations: Retrospective; selection bias due to excluding significant number of patients with missingness

Findings: The risk score developed by DT accurately discriminated between low and high-risk of death with an AUC of 0.88. External validation in two separate HF populations gave AUCs of 0.84 and

0.81 .

Location: United Kingdom

Aim: Predicting long-term mortality after ACS using laboratory values.

Variables: Hematological indices and inflammation markers Strengths: Large sample size

[83], 2019-3b

Limitations: Imputation for the ML was performed using mean of all observations, the latter is typically not ideal since missing in EHR data tend to be not-at-random

Findings: The model achieved a c-statistic of 0.89 for in-hospital mortality. C-statistic was 0.77 for six-month mortality. Red cell distribution width (HR 1.23) and neutrophil to lymphocyte ratio (HR 1.08) showed independent association with all-cause mortality in multivariable Cox regression. 
Table 1. Cont.

\begin{tabular}{|c|c|c|c|}
\hline Ref., Year-Category ** & Study Details & $\begin{array}{l}\text { Sample } \\
\text { Size }\end{array}$ & Algorithms \\
\hline [85], 2019-3b & $\begin{array}{l}\text { Location: China } \\
\text { Aim: Developing a DL model to predict major adverse cardiac } \\
\text { events after ACS. } \\
\text { Variables: } 232 \text { static feature types and } 2194 \text { dynamic feature types. } \\
\text { Strengths: Large sample size; comparison to previous models } \\
\text { Limitations: Retrospective; missing values (up to } 30 \% \text { ) were } \\
\text { imputed using median of all the observations; variables with more } \\
\text { than } 30 \% \text { missing were excluded } \\
\text { Findings: The best model presented had an AUC of } 0.713 \text { and an } \\
\text { accuracy of } 0.764 \text {. } \\
\text { Notable facts: The proposed model adapted to leverage dynamic } \\
\text { treatment information in EHR data boosted the performance of } \\
\text { major adverse cardiac event prediction for ACS. }\end{array}$ & 2930 & RNN \\
\hline
\end{tabular}

\section{Location: Israel}

Aim: Predicting mortality at 30-days in STEMI patients and to compare these to the conventional validated risk scores.

Variables: 54 variables; performance of most models plateaued with

$$
15 \text { variables }
$$

Strengths: Large sample size

[80], 2017-3b

Limitations: Retrospective

Findings: ML models AUC range: 0.64 to 0.91 . The best models had similar or better performance compared to standard scoring

methods. Top predictors were creatinine, Killip class on admission, blood pressure, glucose level, and age.

Notable facts: The algorithms selected showed competence in prediction across an increasing number of variables.

\section{Location: Canada}

Aim: Assessing the prognostication of NN in HF patients using CPET data as opposed to using summary indicators alone.

Variables: Detailed CPET data

Strengths: Using various ML models

Limitations: Retrospective

[112], 2018-3a Findings: NN incorporating breath-by-breath data achieved the

best performance (AUC $=0.842$ ). All models outperformed

NB, DT, LR, rules-based classification tree, $\mathrm{RF}$, Adaptive Boosting summary indices (AUC $\leq 0.800$ ). When compared with the CPET risk score $(A U C=0.759)$, the top-performing model obtained a net reclassification index of $4.9 \%$.

Notable facts: The current practice of considering summary indices in isolation fails to realize the full value of CPET data. Higher data resolution leads to improved prediction.

\section{Location: China}

Aim: Using ML to predict one-year mortality rate of anterior

STEMI patients and comparing to conventional risk scores.

Variables: 59 features; including all features as opposed to top 20 provided better performance

[81], 2020-3b Strengths: Using six different ML algorithms Limitations: Retrospective XGBoost

Findings: AUC of ML models ranged from 0.709 to 0.942. XGBoost achieved the highest accuracy (92\%), specificity (99\%) and f1 score

$(0.72)$ for predictions with the full variable model. After feature selection, XGBoost still obtained the highest accuracy (93\%), specificity (99\%) and f1 score (0.73). 
Table 1. Cont.

\begin{tabular}{|c|c|c|c|}
\hline Ref., Year-Category ** & Study Details & $\begin{array}{l}\text { Sample } \\
\text { Size }\end{array}$ & Algorithms \\
\hline [105], 2019-4b & $\begin{array}{l}\text { Location: United States } \\
\text { Aim: Using ML on EHR data to predict CRT outcome. } \\
\text { Variables: Demographics, laboratory values, medications, clinical } \\
\text { characteristics, and past health services utilization, bigrams (i.e., } \\
\text { two-word sequences) in EHR data } \\
\text { Strengths: Comparing various ML models } \\
\text { Limitations: No distinction between the type of CRT implant. } \\
\text { Findings: The final model identified } 26 \% \text { of patients having a } \\
\text { reduced benefit from the CRT device at a PPV of } 79 \% \text { (model } \\
\text { performance: F } \beta \text { ( } \beta=0.1 \text { ): } 77 \% \text {; recall } 0.26 \text {; precision } 0.79 \text {; accuracy } \\
0.65 \text { ). } \\
\text { Notable facts: A ML model that leveraged readily available EHR } \\
\text { data and clinical notes identified a subset of CRT patients who may } \\
\text { not benefit from CRT before the procedure. }\end{array}$ & 990 & LR, SVM, RF and GBM \\
\hline [113], 2019-1a & $\begin{array}{l}\text { Location: Japan } \\
\text { Aim: Assessing stroke risk by ML using integrated risk factors. } \\
\text { Variables: } 47 \text { features comprised of } 13 \text { conventional risk factors and } \\
34 \text { carotid ultrasound image-based phenotypes (carotid } \\
\text { intima-media thickness, carotid plaque and carotid artery stenosis) } \\
\text { Strengths: Using integrated risk factors } \\
\text { Limitations: Retrospective; small sample size; data imbalance (12 } \\
\text { high-risk patients vs. } 190 \text { low-risk patients) } \\
\text { Findings: ML with integrated risk factors (AUC }=0.80 \text { ) showed an } \\
\text { improvement of } ~ 18 \% \text { against conventional ML (AUC }=0.68 \text { ). } \\
\text { Notable facts: ML model integrated with the event-equivalent gold } \\
\text { standard as percentage stenosis is powerful and offers low cost and } \\
\text { high-performance stroke risk assessment. }\end{array}$ & 202 & RF \\
\hline
\end{tabular}

AI in Treatment Strategies

\section{Location: Multi-national}

Aim: Using ML to phenotypically classify a heterogeneous HF cohort and aid in optimizing the rate of responders to specific therapies.

Variables: 50 variables including clinical parameters, biomarker values, and measures of left and right ventricular structure and function

Strengths: Data from MADIT-CRT trial [114]; randomized cohort

Limitations: Possibility of selection bias; results confined to a selected population of HF patients enrolled in a clinical trial with robust inclusion/exclusion criteria

[99], 2018-3a, 4a
Findings: Four phenogroups identified, significantly different in the primary outcome occurrence. Two phenogroups included a higher proportion of known clinical characteristics predictive of

CRT response and were associated with a substantially better treatment effect of CRT-D on the primary outcome ( $\mathrm{HR}=0.35$ and $\mathrm{HR}=0.36$ ) than observed in the other groups.

Notable facts: By integrating clinical parameters and full heart cycle imaging data, unsupervised ML can provide a clinically meaningful classification of a phenotypically heterogeneous HF cohort and might aid in optimizing the rate of responders to specific therapies.
Multiple Kernel Learning, $\mathrm{K}$-means clustering 
Table 1. Cont.

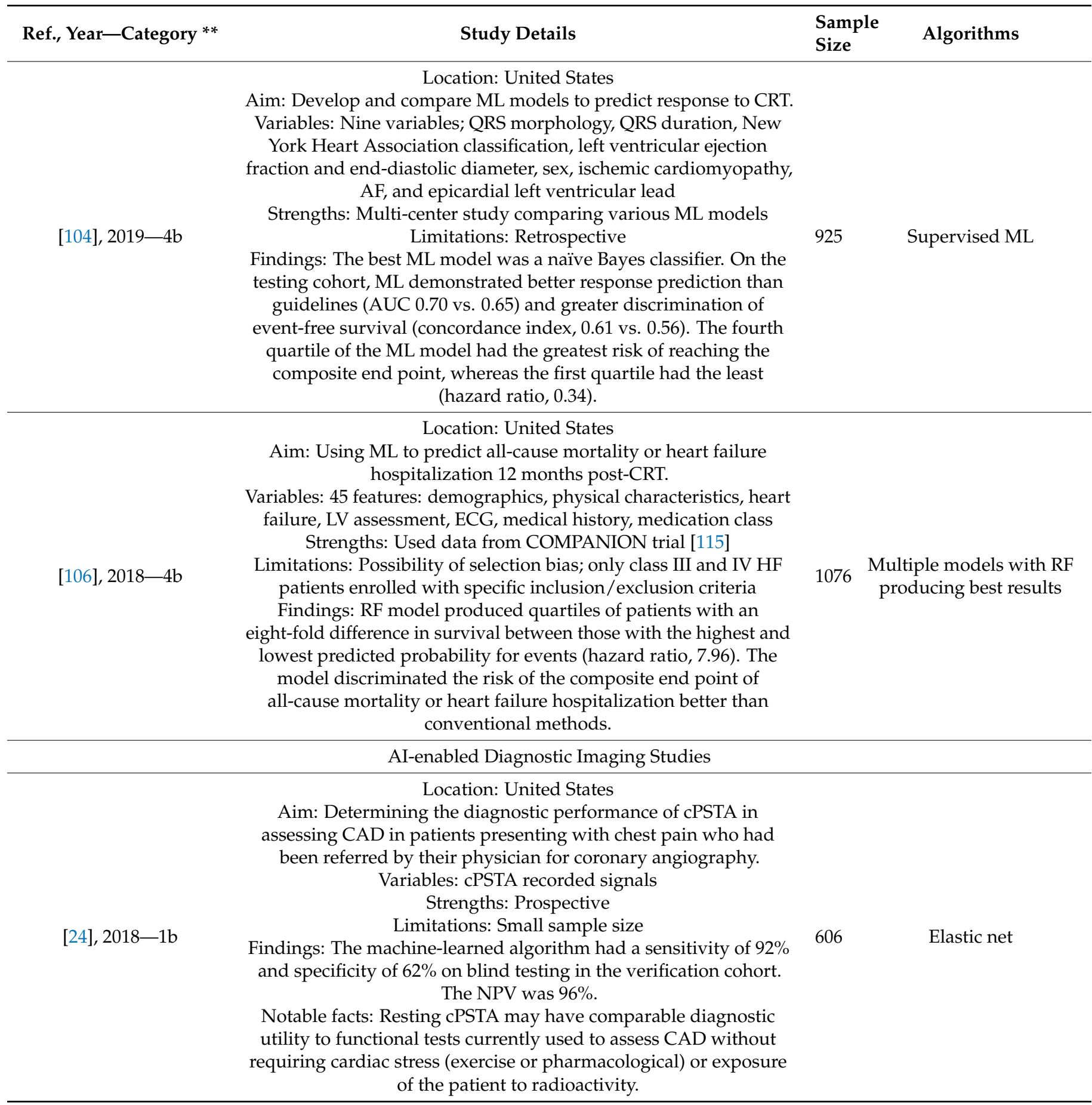


Table 1. Cont.

\begin{tabular}{|c|c|c|c|}
\hline Ref., Year-Category ** & Study Details & $\begin{array}{l}\text { Sample } \\
\text { Size }\end{array}$ & Algorithms \\
\hline$[25], 2018-1 b, 3 a$ & $\begin{array}{l}\text { Location: Multi-national } \\
\text { Aim: Predicting lesion-specific ischemia by invasive FFR using an } \\
\text { integrated ML ischemia risk score from quantitative plaque } \\
\text { measures from CCTA. } \\
\text { Variables: Quantitative CTA data: stenosis, NCP, low-density NCP } \\
\text { (LD-NCP), calcified and total plaque volumes, contrast density } \\
\text { difference (maximum difference in luminal attenuation per unit } \\
\text { area) and plaque length } \\
\text { Strengths: Multi-center data from NXT trial [116] } \\
\text { Limitations: Small sample size; plaque findings were not confirmed } \\
\text { by invasive intravascular ultrasound } \\
\text { Findings: Information gain for predicting ischemia was highest for } \\
\text { contrast density difference (0.172), followed by LD-NCP (0.125), } \\
\text { NCP (0.097), and total plaque volumes (0.092). ML had higher } \\
\text { AIUC (0.84) than individual CTA measures, including stenosis } \\
\text { (0.76), LD-NCP volume (0.77), total plaque volume (0.74) and } \\
\text { pre-test likelihood of CAD (0.63). }\end{array}$ & 254 & LogitBoost \\
\hline
\end{tabular}

\section{Location: Multi-national}

Aim: Evaluate the prognostic value of fully automated DL-based

EAT volume and attenuation quantified from non-contrast cardiac

$$
\text { CT. }
$$

Variables: Non-contrast cardiac CT scan data, inflammatory biomarkers

Strengths: Data from the EISNER trial [23]

Limitations: Long-term follow-up not obtained

[15], 2020-1a Findings: Increased EAT volume and decreased EAT attenuation were independently associated with MACE. CAD risk score, CAC, and EAT volume were associated with increased risk of MACE (hazard ratio: 1.03, 1.25, and 1.35). EAT attenuation was inversely associated with MACE (hazard ratio: 0.83, Harrell C statistic: 0.76). MACE risk progressively increased with EAT volume $\geq 113 \mathrm{~cm}^{3}$ and $\mathrm{CAC} \geq 100 \mathrm{AU}$; highest in subjects with both. EAT volume

correlated with inflammatory biomarkers; EAT attenuation inversely related to inflammatory biomarkers.

\section{Location: Multi-national}

Aim: Investigating whether a ML score, using only plaque stenosis and composition information from the 16 coronary segments, has better predictive accuracy compared to the traditional CCTA based risk scores.

Variables: 16 segment based coronary stenosis $(0 \%, 1-24 \%, 25-49 \%$, $50-69 \%, 70-99 \%$ and $100 \%$ ) and composition (calcified, mixed and non-calcified plaque) derived from CCTA

Strengths: Data from CONFIRM registry [110]

Findings: ML-based approach showed better AUC for event discrimination (0.771) vs. other scores (ranging from 0.685 to 0.701 ). Improved risk stratification was the result of down-classification of risk among patients that did not experience events (non-events). 
Table 1. Cont.

\begin{tabular}{|c|c|c|c|}
\hline Ref., Year-Category ** & Study Details & $\begin{array}{l}\text { Sample } \\
\text { Size }\end{array}$ & Algorithms \\
\hline$[26], 2018-1 b, 1 c, 2 c$ & $\begin{array}{l}\text { Location: Multi-national } \\
\text { Aim: Evaluating DL-based automatic prediction of obstructive } \\
\text { disease from MPI, compared with TPD. } \\
\text { Variables: MPI recorded data } \\
\text { Strengths: Multi-center study } \\
\text { Limitations: Retrospective; degree of stenosis from invasive } \\
\text { angiography was interpreted visually } \\
\text { Findings: AUC for DL was higher than for TPD (per patient: } 0.80 \\
\text { vs. 0.78; per-vessel: 0.76 vs. 0.73). Sensitivity per patient improved } \\
\text { from 79.8\% (TPD) to } 82.3 \% \text { (DL), and per-vessel sensitivity } \\
\text { improved from } 64.4 \% \text { (TPD) to } 69.8 \% \text { (DL). }\end{array}$ & 1018 & DCNN \\
\hline$[52], 2018-2 c, 2 d$ & $\begin{array}{l}\text { Location: United States } \\
\text { Aim: Evaluating the effectiveness of using Computer-Aided } \\
\text { Diagnosis in the triage of low to intermediate risk emergency chest } \\
\text { pain patients with CCTA. } \\
\text { Variables: Data from } 64 \text { and } 320 \text { slice CCTA scanners } \\
\text { Strengths: Looking at } 30 \text {-day outcome } \\
\text { Limitations: Retrospective } \\
\text { Findings: Sensitivity: } 85 \% \text {; specificity: } 50.6 \% \text { and } 56.5 \% \text { for the } 64 \\
\text { and } 320 \text { slice scanners. NPV: } 97.8 \text { and } 97.1 \text { for the } 64 \text { and } 320 \text { slice } \\
\text { scanners. AUC: } 0.6794 \text { and } 0.7097 \text { for the } 64 \text { and } 320 \text { slice scanners. } \\
\text { Software unable to read } 18 \% \text { of the cases. }\end{array}$ & 923 & $\begin{array}{l}\text { Computer aided diagnosis } \\
\text { software }\end{array}$ \\
\hline$[118], 2018-2 \mathrm{c}$ & $\begin{array}{c}\text { Location: Multi-national } \\
\text { Aim: Improving diagnostic performance of CTA to potentially } \\
\text { reducing the number of unnecessary referrals for invasive coronary } \\
\text { angiography. } \\
\text { Variables: } 28 \text { variables from CTA data } \\
\text { Strengths: Multi-center } \\
\text { Limitations: Retrospective; possibility of selection bias due to the } \\
\text { inclusion of patients with the disease only } \\
\text { Findings: ML-FFR (AUC }=0.84 \text { ) and CFD-FFR (AUC }=0.84 \text { ) } \\
\text { outperformed visual CTA (AUC }=0.69 \text { ). Per-vessel and per-patient } \\
\text { diagnostic accuracy improved } 78 \% \text { and } 85 \% \text {, respectively. ML-FFR } \\
\text { correctly reclassified } 73 \% \text { of false-positive CTA results. } \\
\text { Notable facts: On-site ML-FFR improves the performance of CTA } \\
\text { by correctly reclassifying hemodynamically nonsignificant stenosis } \\
\text { and performs equally well as CFD-FFR. }\end{array}$ & 351 & NN \\
\hline
\end{tabular}


Table 1. Cont.

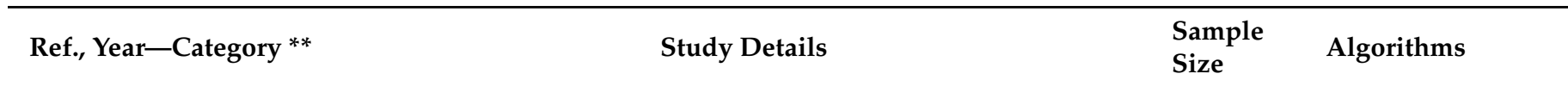

\section{Location: United States}

Aim: Evaluating the incremental benefit of ML-powered resting

myocardial CTP over coronary CT stenosis for predicting ischemia Variables: CCTA and FFR data

Strengths: Data from DeFACTO study [119]

Limitations: Small sample size

[27], 2017-1b, 1c CTP were $68.3 \%, 52.7 \%, 84.6 \%, 78.2 \%$, and $63.0 \%$, respectively, for predicting ischemia. Addition of resting CTP improved Gradient boosting
classifier reclassification improvement: 0.52 ) of ischemia compared to $\mathrm{CT}$ stenosis alone (AUC $=0.68)$.

Notable facts: The addition of resting CTP analysis acquired from ML techniques may improve the predictive utility of significant ischemia over coronary stenosis.

** Category definition: Category 1: Application of AI in pre-diagnosis modeling: primary prevention (1a: Risk Estimation, 1b: Clustering/patient profiling before the event, 1c: Care gap identification and personalized prevention, 1d: Personalized prevention). Category 2: Application of AI in diagnosis and acute-phase treatment (2a: EMS proper referral, 2b: Acute Diagnosis, 2c: Acute Imaging, 2d: Triaging and Acute Treatment). Category 3: Application of AI in post-diagnosis outcome prediction and secondary prevention (3a: Personalize Treatment, 3b: Outcome prediction/effect disposition). Category 4: Application of AI in rehabilitation (4a: Personalize Treatment, 4b: Outcome Prediction). Abbreviations: ACM: all-cause mortality; ACS: acute coronary syndrome; AF: atrial fibrillation; ANN: artificial neural networks; AUC: area under the receiver operating characteristic curve; BN: Bayesian network; CPET: cardiopulmonary exercise testing; CAC: coronary artery calcium score; CAD: coronary artery disease; CAD-RADS: coronary artery disease reporting and data system; CCTA: coronary computed tomographic angiography; CTA: computed tomographic angiography; CCL: cardiac catheterization laboratory; CDS: clinical decision support; CFD: computational fluid dynamics; CHF: congestive heart failure; CHD: coronary heart disease; CNN: convolutional neural network; CONFIRM: Coronary CT Angiography Evaluation For Clinical Outcomes: An International Multi-center; CPSTA: cardiac phase space tomography analysis; CRT: cardiac resynchronization therapy; CTP: computed tomography perfusion; CVD: cardiovascular disease; DL: deep learning; DCNN: deep-learning convolution neural network; DI: modified Duke index; DT: decision tree; DTE: decision tree ensembles; EAT: epicardial adipose tissue; EMS: emergency medical services; ER: emergency room; FFR: fractional flow reserve; FLEMENGHO: Flemish Study of Environment Genes and Health Outcomes; FRS: Framingham risk score; GBM: gradient boosting machines; HCM: hypertrophic cardiomyopathy; HF: heart failure; HFpEF: heart failure with preserved ejection fraction; KNN: k-nearest neighbors; LASSO: least absolute shrinkage and selection operator; LDA: linear discriminant analysis; LR: linear regression; MACE: major adverse cardiac events; MESA: Multi-Ethnic Study of Atherosclerosis; MI: myocardial infarction; ML: machine learning; NB: Naïve Bayesian; NCP: non-calcified plaque; NN: neural networks; PCA: principal components analysis; PCI: percutaneous coronary intervention; PH: pulmonary hypertension; PPV: positive predictive value; RF: random forest; SCD: sudden cardiac death; SIS: segment involvement score; SSS: segment stenosis score; STEMI: ST-elevation MI; SVM: support vector machine; TSH: thyrotropin; TPD: total perfusion deficit.

Table 2. Cerebrovascular studies using artificial intelligence.

\begin{tabular}{|c|c|c|c|}
\hline Ref., Year-Category ** & Study Details & $\begin{array}{l}\text { Sample } \\
\text { Size }\end{array}$ & Algorithms \\
\hline \multicolumn{4}{|c|}{ AI and Risk Stratification Modeling } \\
\hline [18], 2019-1a & $\begin{array}{c}\text { Location: China } \\
\text { Aim: Proposed a new feature selection method to select } \\
\text { important risk factors for detecting ischemic stroke. } \\
\text { Variables: } 24 \text { blood test features and four demographic } \\
\text { features } \\
\text { Limitations: Single-center study } \\
\text { Findings: Top nine features selected. Sensitivity: } 82.7 \% \text {, } \\
\text { specificity: } 80.4 \% \text {, classification accuracy: } 81.5 \% \text {, Youden } \\
\text { index: } 0.63 \text {. }\end{array}$ & 792 & $\begin{array}{c}\text { Weighting and ranking-based } \\
\text { hybrid feature selection } \\
\text { (WRHFS) }\end{array}$ \\
\hline
\end{tabular}


Table 2. Cont.

\begin{tabular}{|c|c|c|c|}
\hline Ref., Year-Category ** & Study Details & $\begin{array}{l}\text { Sample } \\
\text { Size }\end{array}$ & Algorithms \\
\hline [19], 2017-1a & $\begin{array}{c}\text { Location: China } \\
\text { Aim: Build 2-year thromboembolism prediction models } \\
\text { for AF patients, } \\
\text { Variables: Chinese AF Registry data } \\
\text { Strengths: Large dataset, two-year follow-up } \\
\text { Limitations: Retrospective; design of the preprocessing } \\
\text { and imputation strategy could lead to bias results and } \\
\text { model overfitting } \\
\text { Findings: AUC: } 0.71-0.74 \text {. } \\
\text { Notable facts: Model superior to previous } \\
\text { thromboembolism prediction models. }\end{array}$ & 3535 & LR, Cox, NB, CART, RF \\
\hline$[20], 2018-1 a$ & $\begin{array}{c}\text { Location: China } \\
\text { Aim: Build one-year ischemic stroke prediction models for } \\
\text { AF patients. } \\
\text { Variables: Chinese AF Registry data } \\
\text { Strengths: Large dataset } \\
\text { Limitations: Retrospective; highly imbalanced dataset } \\
\text { (3.8\% rate of stroke at one-year) } \\
\text { Findings: AUC: } 0.714 \text {. } \\
\text { Notable facts: Boots-wrapper can balance model } \\
\text { discrimination and statistical significance of features for } \\
\text { developing AF stroke prediction models. }\end{array}$ & 3736 & $\begin{array}{l}\text { Bootstrap-based wrapper for } \\
\text { feature selection }\end{array}$ \\
\hline [21], 2019-1a & $\begin{array}{c}\text { Location: Taiwan } \\
\text { Aim: Develop a predictive model to estimate three-year } \\
\text { risk of ischemic stroke in the general population. } \\
\text { Variables: Insurance claim data } \\
\text { Strengths: Large sample size; model maintained high } \\
\text { predictability five years after being developed. } \\
\text { Limitations: Retrospective } \\
\text { Findings: AUC: } 0.920 \text { (95\% CI, } 0.908-0.932 \text { ) in testing } \\
\text { dataset } 1 \text { and } 0.925 \text { ( } 95 \% \text { CI, } 0.914-0.937) \text { in testing dataset } \\
\text { 2. Sensitivity and specificity were } 80.3-92.5 \% \text { and } \\
79.8-87.5 \% \text { for testing dataset } 1 ; 83.7-91.8 \% \text { and } \\
79.9-87.5 \% \text { for testing dataset } 2 \text {. } \\
\text { Notable facts: DNN algorithm is capable of obtaining a } \\
\text { high performing model for assessment of ischemic stroke } \\
\text { risk. }\end{array}$ & 840,487 & DNN \\
\hline [93], 2019-3b & $\begin{array}{c}\text { Location: China } \\
\text { Aim: Identify the ischemic stroke readmission risk factors } \\
\text { and establish a } 90 \text {-day readmission prediction model for } \\
\text { first-time ischemic stroke patients. } \\
\text { Variables: Clinical data } \\
\text { periods } \\
\text { Ptrengths: Compared predictions at various follow-up } \\
\text { pimitations: Retrospective; imputation of missing values } \\
\text { is not discussed; dataset highly imbalanced ( } 8.6 \% \\
\text { readmission rate) } \\
\text { Findings: Standard AUC: } 0.782(0.729-0.834) \text {; best } \\
\text { time-dependent AUC : } 0.808 \text { in } 54 \text { days. } \\
\text { Notable facts: XGboost model obtained a better risk } \\
\text { prediction for } 90-\text { day readmission for first-time ischemic } \\
\text { stroke patients than the LR model. }\end{array}$ & 6070 & XGBoost, LR \\
\hline
\end{tabular}


Table 2. Cont.

\begin{tabular}{|c|c|c|c|}
\hline Ref., Year-Category ** & Study Details & $\begin{array}{l}\text { Sample } \\
\text { Size }\end{array}$ & Algorithms \\
\hline \multicolumn{4}{|c|}{ AI-enabled Diagnostic Studies } \\
\hline$[42], 2017-2 b, 2 d$ & $\begin{array}{c}\text { Location: USA } \\
\text { Aim: Recognize acute cerebral ischemia and differentiate } \\
\text { that from stroke mimics at the initial examination. } \\
\text { Variables: Clinical data } \\
\text { Strengths: Prospective; ten-fold cross-validation } \\
\text { Limitations: Stroke subtypes not classified } \\
\text { Findings: Sensitivity: } 80.0 \%(95 \% \text { CI, } 71.8-86.3) \text {; } \\
\text { specificity: } 86.2 \%(95 \% \text { CI, } 78.7-91.4) ; \text { median precision: } \\
92 \%(95 \% \text { CI, } 88.7-95.3) \text {. } \\
\text { Notable facts: ANN can be an effective tool to recognize } \\
\text { ACI and differentiate it from stroke mimics at the initial } \\
\text { examination. }\end{array}$ & 260 & ANN \\
\hline [49], 2019-2b & $\begin{array}{c}\text { Location: Korea } \\
\text { Aim: Detecting stroke and modeling mortality; stroke } \\
\text { definition based on ICD code. } \\
\text { Variables: Gender, age, type of insurance, admission type, } \\
\text { brain surgery required, region, LOS, hospital location, } \\
\text { number of hospital beds, stroke type, and CCI } \\
\text { Strengths: Large sample size } \\
\text { Limitations: Retrospective } \\
\text { Findings: AUC: } 83.48 \% \text {. } \\
\text { Notable facts: A scaled PCA/deep neural network } \\
\text { approach can be used by both patients and doctors to } \\
\text { prescreen for possible stroke. }\end{array}$ & 15,099 & $\begin{array}{c}\text { PCA, DNN, RF, GNB, KNNC, } \\
\text { SVM, ADB }\end{array}$ \\
\hline [45], 2019-2b, 2c & $\begin{array}{c}\text { Location: Sweden } \\
\text { Aim: Detecting intracranial bleeding using simulated } \\
\text { microwave transmission data, leveraging numerical } \\
\text { simulation based on 3D finite-difference time-domain } \\
\text { modeling. } \\
\text { Variables: Computational model from an anatomical } \\
\text { tissue of a human head; bleeding model is simplified } \\
\text { representation of intracranial bleeding (resembling acute } \\
\text { phase) } \\
\text { Strengths: Simulated cohort } \\
\text { Limitations: Retrospective } \\
\text { Findings: With a sample size that approached } 1000 \\
\text { subjects, classification results characterized as AUC > 0.9. } \\
\text { Notable facts: Results indicate very high sensitivity and } \\
\text { specificity. }\end{array}$ & $\begin{array}{l}\text { Synthetic } \\
\text { cohort }\end{array}$ & $\mathrm{BC}$ \\
\hline$[94], 2019-3 b$ & $\begin{array}{c}\text { Location: China } \\
\text { Aim: Identifying high-risk TIA or minor stroke patients } \\
\text { (recurrent ischemic stroke within one year). } \\
\text { Variables: Demographics, clinical and imaging data } \\
\text { Strengths: Patients with stroke or TIA mimics were } \\
\text { excluded } \\
\text { Limitations: Retrospective; downsampling the majority } \\
\text { class applied to address data imbalance } \\
\text { Findings: ANN median sensitivity: } 75 \% \text {; specificity: } 75 \% \text {; } \\
\text { accuracy: } 75 \% \text {; c statistic: } 0.77 \text {. } \\
\text { Notable facts: ANN model outperformed SVM and Naïve } \\
\text { Bayes. }\end{array}$ & 451 & ANN, SVM, NB \\
\hline
\end{tabular}


Table 2. Cont.

\begin{tabular}{|c|c|c|c|}
\hline Ref., Year-Category ** & Study Details & $\begin{array}{c}\text { Sample } \\
\text { Size }\end{array}$ & Algorithms \\
\hline$[46], 2019-2 b, 2 c$ & $\begin{array}{c}\text { Location: USA } \\
\text { Aim: Detecting acute intracranial hemorrhage on head CT } \\
\text { scans using DL. } \\
\text { Variables: CT scan data } \\
\text { Strengths: Large sample size } \\
\text { Limitations: Retrospective } \\
\text { Findings: AUC: } 0.991 \pm 0.006 \text {. } \\
\text { Notable facts: Demonstrated end-to-end network that } \\
\text { performs joint classification and segmentation with } \\
\text { examination-level classification comparable to experts, in } \\
\text { addition to robust localization of abnormalities. }\end{array}$ & 4596 & FCN \\
\hline$[60], 2018-2 d$ & $\begin{array}{c}\text { Location: USA } \\
\text { Aim: Classifying acute ischemic stroke onset time. } \\
\text { Variables: MRI features } \\
\text { Strengths: Extracted hidden representations from the MR } \\
\text { perfusion-weighted images } \\
\text { Limitations: Retrospective; possibly selection bias due to } \\
\text { missingness; only 10\% of patients had sufficient } \\
\text { information to be included in the study } \\
\text { Findings: AUC: } 0.68 \text {. } \\
\text { Notable facts: Classification significantly improved over } \\
\text { current clinical methods, demonstrating the potential } \\
\text { benefit of using ML methods in TSS classification. }\end{array}$ & 105 & FLIRT, SMR, SVM, RF, GBRT \\
\hline \multicolumn{4}{|c|}{ AI in Outcome Prediction/Prognosis } \\
\hline$[96], 2018-3 a, 3 b$ & $\begin{array}{c}\text { Location: USA } \\
\text { Aim: Developing and validating model for delayed } \\
\text { cerebral ischemia after subarachnoid hemorrhage. } \\
\text { Variables: Age, sex, Hunt-Hess grade, modified Fisher } \\
\text { Scale (mFS), and Glasgow Coma Scale (GCS) } \\
\text { Strengths: Prospective } \\
\text { Limitations: Possibility of selection bias; patients with } \\
\text { missingness excluded } \\
\text { Findings: Standard grading scale (mFS): AUC 0.58; } \\
\text { combined demographics and grading scales: AUC 0.60; } \\
\text { random kernel derived physiologic features: AUC 0.74; } \\
\text { combined baseline and physiologic features with } \\
\text { redundant feature reduction: AUC 0.77. }\end{array}$ & 488 & PLS, linear \& kernel SVM \\
\hline$[91], 2019-3 b$ & $\begin{array}{l}\text { Location: Korea } \\
\text { Aim: Predict the three-month outcomes (mRS) in ischemic } \\
\text { stroke patients. } \\
\text { Variables: Clinical data } \\
\text { Strengths: Large sample size } \\
\text { Limitations: Retrospective } \\
\text { Findings: DNN AUC was significantly higher than that of } \\
\text { the ASTRAL score }(0.888 \text { vs. } 0.839 ; p<0.001) \text { when } 38 \\
\text { variables were used. When only the six variables from the } \\
\text { ASTRAL score were used in the ML models, there was no } \\
\text { significant difference in performance. }\end{array}$ & 2604 & DNN, RF, LR \\
\hline
\end{tabular}


Table 2. Cont.

\begin{tabular}{|c|c|c|c|}
\hline Ref., Year-Category ** & Study Details & $\begin{array}{l}\text { Sample } \\
\text { Size }\end{array}$ & Algorithms \\
\hline [95], 2018-3a, 3b & $\begin{array}{l}\text { Location: Netherlands } \\
\text { Aim: Predicting the outcome of endovascular treatment } \\
\text { for acute ischemic stroke. } \\
\text { Variables: } 53 \text { baseline variables and } 30 \text { treatment variables } \\
\text { Strengths: Large sample size } \\
\text { Limitations: Retrospective } \\
\text { Findings: Range mean AUC }=0.88-0.91 \text { with a negligible } \\
\text { difference of mean AUC }(0.01 ; 95 \% C I \text { : } 0.00-0.01) \text { between } \\
\text { best performing ML algorithm (RF) and best performing } \\
\text { LR model. } \\
\text { Notable facts: In large vessel occlusion patients, ML did } \\
\text { not outperform LR models in predicting reperfusion and } \\
\text { three-month functional independence after endovascular } \\
\text { treatment. Radiological outcome was more difficult to } \\
\text { predict than clinical outcome at time of admission. }\end{array}$ & 1383 & $\begin{array}{l}\text { Super Learner (ensemble } \\
\text { method), RF, SVM, ANN }\end{array}$ \\
\hline [92], 2019-3b & $\begin{array}{c}\text { Location: Switzerland } \\
\text { Aim: Predicting the outcome }(\mathrm{mRS}>2) \text { at } 90 \text { days in } \\
\text { patients with acute ischemic stroke. } \\
\text { Variables: Biomarkers available at admission, NIHSS score } \\
\text { Limitations: Retrospective } \\
\text { Findings: XGB and GBM AUC }=0.746 \text { and } 0.748 \text {; } \\
\text { improved after adding NIHSS and feature selection to } \\
0.884 \text { and } 0.877 \text {, respectively. } \\
\text { Notable facts: DT-based GBMs can predict the recovery } \\
\text { outcome of stroke patients at admission with a high AUC. }\end{array}$ & 512 & XGB, GBM \\
\hline [120], 2018-3a & $\begin{array}{l}\text { Location: China } \\
\text { Aim: Identifying a neurological deterioration prognostic } \\
\text { model, based on dehydration equations. } \\
\text { Variables: age, sex, laboratory values, and vascular risk } \\
\text { factor data } \\
\text { Strengths: Feature selection by the Boruta algorithm } \\
\text { Limitations: Retrospective } \\
\text { Findings: After decreasing the number of variables from } \\
18 \text { to 5, the specificity of test samples for the SVM } \\
\text { prediction model increased from } 44.1 \% \text { to } 89.4 \% \text {, and the } \\
\text { AUC increased from } 0.700 \text { to } 0.927 \text {. } \\
\text { Notable facts: SVM algorithms can be used to establish a } \\
\text { prediction model for dehydration-associated ND, with } \\
\text { good classification results. }\end{array}$ & 382 & SVM \\
\hline
\end{tabular}

Location: Taiwan

Aim: Prediction of Barthel index (BI) status at discharge to optimize care of post-stroke patients.

Variables: 15 rehabilitation assessments variables Limitations: Retrospective; patients were excluded (43) due to incomplete data; ratio of men to women was 2:1

[100], 2018-4a, 4b
Findings: LR and RF algorithms performed higher (AUC $=0.79$ ) than SVM (AUC = 0.77). Mean absolute error of SVM and LR in predicting BI at discharge were 9.86 and 9.95, respectively.

Notable facts: The proposed ML-based method provides a promising and practical computer-assisted

decision-making tool for predicting ADL in clinical 
Table 2. Cont.

\begin{tabular}{|c|c|c|c|}
\hline Ref., Year-Category ** & Study Details & $\begin{array}{c}\text { Sample } \\
\text { Size }\end{array}$ & Algorithms \\
\hline \multicolumn{4}{|c|}{ AI in Treatment Strategies } \\
\hline [35], 2018-1a, 1b, 1c & $\begin{array}{l}\text { Location: Switzerland } \\
\text { Aim: Investigating whether a CDS tool for stroke } \\
\text { prevention integrated in EHR could improve adherence to } \\
\text { guidelines in patients with AF in a PCP setting. } \\
\text { Strengths: Randomized clinical trial; the analysis was } \\
\text { carried out in a catchment area with high baseline } \\
\text { adherence rate } \\
\text { Findings: No difference observed in the incidence of } \\
\text { stroke, TIA, or systemic thromboembolism in CDS group } \\
\text { vs. control group. CDS group had a lower incidence of } \\
\text { significant bleeding. }\end{array}$ & 444,347 & CDS system \\
\hline [59], 2019-2d & $\begin{array}{c}\text { Location: USA } \\
\text { Aim: Develop a regression tree model predict 90-day } \\
\text { modified Rankin Scale (mRS) scores to aid with ET. } \\
\text { Variables: Elderly patients defined as } \geq 80 \text { years of age } \\
\text { Strengths: Retrospective and prospective; the model } \\
\text { validated using an independent prospective cohort (36) of } \\
\text { patients presenting to the same institution } \\
\text { Limitations: Small sample size } \\
\text { Findings: Sensitivity: } 89.36 \% \text {; specificity: } 89.66 \% \text {; AUC: } \\
0.952 . \\
\text { Notable facts: Algorithm is useful to determine which } \\
\text { patients to exclude from ET, and has been implemented in } \\
\text { an online calculator for public use. }\end{array}$ & 110 & Regression tree \\
\hline \multicolumn{4}{|c|}{ AI-enabled Diagnostic Imaging Studies } \\
\hline$[47], 2018-2 b, 2 c, 2 d$ & $\begin{array}{l}\text { Location: USA } \\
\text { Aim: Detecting and quantifying intraparenchymal, } \\
\text { epidural, subdural and subarachnoid hemorrhages on } \\
\text { non-contrast CT (NCCT) and estimating hemorrhage } \\
\text { volume. } \\
\text { Variables: Training set: } 10,159 \text { NCCT examinations, } 901 \text { of } \\
\text { which contained hemorrhage. Testing set: } 682 \text { prospective } \\
\text { NCCT examinations, } 82 \text { of which contained hemorrhage } \\
\text { Strengths: Retrospective and prospective evaluation } \\
\text { Findings: Hemorrhage detection accuracy: } 0.970, \text { AUC: } \\
\text { 0.981, sensitivity: } 0.951 \text {, specificity: } 0.973, \text { PPV: } 0.829 \text {, and } \\
\text { NPV: 0.993. Dice scores for intraparenchymal hemorrhage: } \\
\text { 0.931, epidural/subdural hemorrhage: } 0.863 \text {. SAH: } 0.772 \text {. }\end{array}$ & 10,841 & $\mathrm{CNN}$ \\
\hline$[55], 2019-2 c, 2 d$ & $\begin{array}{c}\text { Location: International } \\
\text { Aim: Segmentation and phenotyping of acute ischemic } \\
\text { lesions on MRI. } \\
\text { Variables: MRI data } \\
\text { Strengths: Single-center cohort: } 267 \text {; MRI-GENIE cohort } \\
\text { (from } 12 \text { international centers from the Stroke Genetics } \\
\text { Network): } 3301 \\
\text { Limitations: Retrospective } \\
\text { Findings: No algorithm-specific results reported. } \\
\text { Automated and manual lesion volumes were statistically } \\
\text { correlated. } \\
\text { Notable facts: Deep learning algorithms trained on } \\
\text { diverse data can be successfully used for segmentation of } \\
\text { clinical diffusion-weighted MRI lesions. }\end{array}$ & 3568 & $\mathrm{CNN}$ \\
\hline
\end{tabular}


Table 2. Cont.

\begin{tabular}{|c|c|c|c|}
\hline Ref., Year-Category ** & Study Details & $\begin{array}{c}\text { Sample } \\
\text { Size }\end{array}$ & Algorithms \\
\hline$[48], 2019-2 b, 2 c$ & $\begin{array}{c}\text { Location: China } \\
\text { Aim: Detecting ICH and subtypes (cerebral, parenchymal, } \\
\text { intraventricular, subdural, epidural, and subarachnoid) in } \\
\text { NCCT. } \\
\text { Variables: CT scan image slices data } \\
\text { Strengths: Multi-institutional } \\
\text { Limitations: Retrospective; prevalence of ICH (65\%) was } \\
\text { higher than that in a real clinical setting; limited number } \\
\text { of cases in some subtypes (case/control ratio of } 1: 14) \text {; } \\
\text { comparison was made with junior radiology trainees } \\
\text { Findings: AUC (detecting ICH): } 0.98 \text {; AUC (detecting } \\
\text { subtype): } 0.8 \text {. }\end{array}$ & 2836 & CNN-RNN \\
\hline$[56], 2019-2 c, 3 b$ & $\begin{array}{c}\text { Location: China } \\
\text { Aim: Predicting hematoma expansion in patients with } \\
\text { spontaneous ICH. } \\
\text { Variables: Fibrinogen level, sex, Glasgow Coma Score, } \\
\text { time to initial CT scan, black hole sign, blend sign, satellite } \\
\text { sign, midline shift, and baseline hematoma volume } \\
\text { Strengths: Large sample size } \\
\text { Limitations: Retrospective } \\
\text { Findings: Sensitivity: } 81.3 \% \text {; specificity: } 84.8 \% \text {; accuracy } \\
\text { of } 83.3 \% \text {; AUC: } 0.89 \text {. } \\
\text { Notable facts: Potential utility in institutions where CTA } \\
\text { is limited. }\end{array}$ & 1157 & SVM \\
\hline [29], 2019-1b, 1c & $\begin{array}{c}\text { Location: Japan } \\
\text { Aim: Detecting cerebral aneurysms at time-of-flight MR } \\
\text { angiography. } \\
\text { Variables: MRA image data } \\
\text { Limitations: Retrospective; variable number of training } \\
\text { samples per aneurysm location } \\
\text { Findings: Sensitivity: } 91-93 \% \\
\text { Notable facts: The model improved aneurysm detection } \\
\text { by } 4.8-13 \% \text { compared with the initial reports. }\end{array}$ & 748 & DL (ResNet) \\
\hline
\end{tabular}

Location: USA

Aim: Using an automated algorithm to detect intracranial LVO on CTA.

Variables: CTA image data

Limitations: Retrospective

Findings: Sensitivity: 92-94\%, NPV: 97-98\%; specificity $0.76-0.81$.

Notable facts: RAPID CTA can be used in the emergent setting as a screening tool to alert radiologists.

Location: USA

Aim: Identifying LVO and ischemic core volume in patients using CTA.

Variables: CTA image data

Strengths: Comparison with RAPID CTA

Limitations: Retrospective; 338 patients excluded mainly due to imaging artifacts/quality

[43], 2019-2b, 2c

Findings: AUC (LVO detection): 0.88; AUC (Ischemic core

detection $\leq 30 \mathrm{~mL}$ ): 0.88; AUC (Ischemic core detection $\leq$

$50 \mathrm{~mL}$ ): 0.90; AUC (early time window): 0.90; AUC (late time window): 0.91 .

Notable facts: CTA has the required information for neuroimaging evaluation of endovascular therapy with potential to be automated by ML. 
Table 2. Cont.

\begin{tabular}{|c|c|c|c|}
\hline Ref., Year-Category ** & Study Details & $\begin{array}{c}\text { Sample } \\
\text { Size }\end{array}$ & Algorithms \\
\hline$[90], 2018-3 b$ & $\begin{array}{c}\text { Location: Denmark } \\
\text { Aim: Use deep learning to identify and combine acute } \\
\text { imaging features of ischemic stroke to predict lesion } \\
\text { volume. } \\
\text { Variables: MRI data } \\
\text { Strengths: Comparing different CNNs } \\
\text { Limitations: Retrospective; no control group; model is } \\
\text { potentially biased toward infarct overestimation } \\
\text { Findings: AUC: } 0.88 \pm 0.12 \text {. } \\
\text { Notable facts: CNN improved prediction accuracy over } \\
\text { current methods. }\end{array}$ & 222 & $\mathrm{CNN}$ \\
\hline
\end{tabular}

\section{Location: USA}

Aim: Distinguishing between hyperacute ischemic lesions and their corresponding contralateral brain tissue in

$$
\text { NCCT }
$$

Variables: CT image data

[54], 2017-2c Limitations: Retrospective; used contralateral hemisphere

SVM, Decision trees, AdaBoost as control possibly capturing old ischemic lesions.

Findings: AUC: 0.82.

Notable facts: Optimal texture features provided to

distinguish between hyperacute ischemic lesions and their corresponding contralateral brain tissue in NCCT.

Location: USA and Australia

Aim: Predicting ischemic core on CT perfusion image. Variables: CT image data

Strengths: Included patients who underwent back-to-back

CT perfusion imaging and MRI

Limitations: Retrospective; possibly overestimating the ischemic core volume (due to the dependency on the arbitrary subregion of the brain)

Findings: AUC (ischemic core prediction): 0.85-0.87;

sensitivity (ischemic core prediction): $0.90-0.91$; specificity

(ischemic core prediction): 0.62-0.65; maximal Dice coefficient: 0.48 .

Notable facts: ANN accurately integrates clinical and CT perfusion imaging data to predict ischemic core.

** Category definition: Category 1: Application of AI in pre-diagnosis modeling: primary prevention (1a: Risk Estimation, 1b: Clustering/patient profiling before the event, 1c: Care gap identification and personalized prevention, 1d: Personalized prevention). Category 2: Application of AI in diagnosis and acute-phase treatment (2a: EMS proper referral, 2b: Acute Diagnosis, 2c: Acute Imaging, 2d: Triaging and Acute Treatment). Category 3: Application of AI in post-diagnosis outcome prediction and secondary prevention (3a: Personalize Treatment, 3b: Outcome prediction/effect disposition). Category 4: Application of AI in rehabilitation (4a: Personalize Treatment, 4b: Outcome Prediction). Abbreviations: ANN: artificial neural network; ADB: AdaBoost classifier; AF: atrial fibrillation; AUC: area under the curve; BC: binary classification; CART: classification and regression tree; CCI: Charlson comorbidity index; CDS: clinical decision support; CT: computed tomography; CTA: computed tomography angiogram; CTP: computed tomography perfusion; DL: deep learning; DNN: deep neural network; DT: decision tree; DWI: diffusion weighted image; EHR: electronic health record; ET: endovascular thrombectomy; FCN: fully convolutional neural network; FLIRT: FMRIB's Linear Image Registration Tool; GBM: gradient boosting machine; GBRT: gradient boosted regression tree; GLM: generalized linear model; GNB: Gaussian naïve Bayes; GRU: Gated Recurrent Unit; ICH: intracranial hemorrhage; KNNC: K-nearest neighbor classifier; LR: linear regression; LOS: length of hospital stay; LVO: large vessel occlusion; FCN: fully convolutional neural network; MRI: magnetic resonance imaging; mRS: modified Rankin Scale score; NB: Naïve Bayes; NIHSS: National Institutes of Health Stroke Scale; PCP: primary care provider; PLS: partial least squares; RF: random forest; ROC: receiver operating characteristic; SMR: stepwise multilinear regression; SVM: support vector machine; TIA: transient ischemic attack; XGB: extreme gradient boosting.

\section{Other Applications of AI}

\subsection{Clinical Trials in the AI-Era}

Patient selection for a clinical trial is a crucial process, and research has shown that predictive modeling in the selection of patients would increase the trials' success rate [121]. 
The development of a drug takes about ten years and more than two billion dollars, and yet only a fraction of drugs are approved by the Food and Drug Administration (FDA) [122]. The application of in silico clinical trials to suggest better patient selection criteria $[123,124]$ can increase the efficiency and speed of drug development. For instance, the use of AI in clinical trials can increase the efficacy of screening of drug candidates based on (a) analysis of calculated properties, (b) prediction models for therapeutic drug targets, and (c) identification of safety liabilities; all of which facilitate a reduction in the number of in vivo or in vitro assay requirements [125]. These efforts are also driven by innovative start-up companies to reduce the cost and improve the success rate of trials.

\subsection{AI at Physicians' Fingertips-Implication and Future Directions}

Once validated and proven effective and safe, the AI solutions have to be integrated into clinical workflow and demonstrated to be effective in improving outcomes. It is only then that we have leaped to provide evidence-based care in real-time using the promises of big data and AI. However, taking the advances in AI to the bedside is not trivial. First, novel AI solutions must be rigorously assessed. Certainly, the FDA approval for AI applications is laying the foundation for regulatory evolution to allow faster integration of AI-enabled technologies into healthcare. Many clinical trials are designed to evaluate the impact of technological advances (such as new imaging devices [126]) like the drug-design trials. Second, carefully designed CDSS need to be developed and implemented in the EHR that take the AI-powered tool to physician's fingertips. To achieve these goals, the American Medical Informatics Association (AMIA) published a roadmap [127] in 2007 for taking action on CDSS and defined three main pillars: (a) high adoption and effective use, (b) best knowledge available when needed, and (c) continuous improvement of knowledge and CDSS methods. However, in general, physicians have relatively positive attitudes toward the idea of CDSS [128,129], even though there are many challenges, including low specificity [130,131], workflow interruptions [132-134], confusing interfaces [135,136], low confidence [137], awareness of the information [138], requirements of manual data entry [134,139], interference with physician autonomy [128,140], or lack of relevance [134] that limit the effective use and adoption of CDSS in many health care systems. "Alert Fatigue" can be caused by poorly designed and implemented CDSS [128,141-143]. The four principles for the design of CDSS interfaces (four A's: All in one, At a glance, At hand, and Attention) [144] should also be followed. Based on the unified theory of acceptance and use of technology [145], user expectations need to be taken into consideration for technology to be accepted. In addition, several studies highlighted the importance of considering the end-user needs and expectations early in the development process $[139,143,146]$. Therefore, it is imperative to have CDSS end-users involved in the design and implementation. It is also essential to consult EHR engineers and information technologists to understand the possibilities, limitations, and hardware/software requirements to effectively utilize CDSS functionalities. Careful planning requires mapping current workflows to understand how clinical phases and tasks are completed and how these may be affected by the addition of CDSS. In some instances, CDSS may need to be customized to suit various processes. Many physicians remain hesitant to accept CDSSs, leading to suboptimal implementation [143]. Finally, despite federal investment to promote health information technology adoption, gaps remain in the use of CDSS among health systems [147], and we believe that lack of physician acceptance may be one of the main reasons. Thus, it is imperative for researchers across the translational spectrum to be involved in this AI revolution so that we can together reach the promises of precision health in a scalable and fair manner.

\subsection{Health Disparity and Implicit Bias}

Although recent scrutiny of AI-based software has introduced concern about unintended effects of AI on social bias and inequity [148], there are opportunities to leverage technology to reduce health disparity, care gaps [149,150], and unwanted variations [151], as well as improving access. There are many examples of how technology is improving 
access to specialty care, especially in rural areas. However, AI-based studies have to be carefully designed with explicit frameworks and a balanced representation of participants to mitigate some of the undesirable biases. For instance, the use of deep transfer learning is effective in reducing healthcare disparities that are driven by data inequality [152]. The reader is referred to the work by Cirillo et al. [153] for a more detailed overview and some of the recommendations on how to improve the global health and disease landscape and decrease inequalities with the use of technology.

There are also other challenges and opportunities when integrating AI tools in clinical workflow; namely, there are technological challenges, operational challenges, and ethical challenges [61]. These issues are tightly intertwined with implicit biases and health disparity. Larger centers with better access to robust infrastructure and a wide range of patient representation are better positioned to address implicit biases and address these challenges, leading to better integration of AI-assistive tools in the clinical workflow. However, as it is impossible - in practical terms - to find solutions to ensure the highest efficacy, efficiency, equity, and patient safety, it is important and necessary to define acceptable thresholds by working meticulously with regulatory institutions to guide the development of $\mathrm{AI}$ tools to ensure best practices and compliance.

\section{Conclusions}

To summarize, we have seen that the field of $\mathrm{AI}$ is omnipresent in both cardio and cerebrovascular fields, targeting different stages of patient management (Figure 2). However, in the cardiovascular field, studies have been larger, and there were more prospective and multi-center studies. In the field of cerebrovascular diseases, studies were mostly retrospectives from single centers and limited in patient representation and scale. By enhancing collaborative efforts, future cerebrovascular studies can expand follow-up periods to better understand the long-term outcomes in the patients. Both cardio- and cerebrovascular fields can also benefit from collaborative efforts to increase data diversity, patient representation, and integration of different data modalities, e.g., imaging biomarkers and genetic information.

Currently, the limitations in AI-based models are mostly centered on the lack of sufficient patient representation, balanced cohorts, and biases introduced by cohort definitions or selection of variables, as well as the exclusion of a certain group of patients. Machine learning models pick up biases from the training datasets; therefore, to reach new heights, it is of fundamental importance to increase patient representation and data density and improve data for downstream modeling [154,155]. Finally, in terms of methodologies, both fields are taking advantage of advances in machine learning frameworks and tools. Ultimately, the future of healthcare is an organic blend of technology, innovation, and human connection. It is not enough to provide faster, better care; we must leverage the technology to also ensure that the care is fair and not biased towards a group or sub-population. We must understand our limitations and use the technology to deliver an integrated solution that does not make the physicians fixed to the screen and the keyboard. The care also has to ensure physicians receive the tools they need to be better at what they do. Overall, there are few areas in which AI can be of great value in both cardio and cerebrovascular diseases: (1) disease diagnosis and patient monitoring, especially in high-impact fields; (2) incidental findings for preventive care by scanning through images and reports; (3) risk stratification for primary or secondary prevention; and (4) resource and workflow optimization by leveraging administrative data.

Author Contributions: Conceptualization: V.A. (Vida Abedi) and R.Z.; Data extraction and preparation: V.A. (Vida Abedi), A.K., A.T. and A.P.; Data Analysis: V.A. (Vida Abedi), A.K., S.-M.R., V.A. (Venkatesh Avula); Writing-Original draft preparation: V.A. (Vida Abedi), A.K. and S.-M.R.; Critical editing of the draft: A.V.S., J.L., R.Z. All authors have read and agreed to the published version of the manuscript.

Funding: The study had no specific funding. 
Institutional Review Board Statement: Not applicable.

Informed Consent Statement: Not applicable.

Data Availability Statement: Not applicable.

Conflicts of Interest: The authors declare no conflict of interest.

\section{References}

1. Noorbakhsh-Sabet, N.; Zand, R.; Zhang, Y.; Abedi, V. Artificial Intelligence Transforms the Future of Health Care. Am. J. Med. 2019, 132, 795-801. [CrossRef] [PubMed]

2. Krittanawong, C.; Zhang, H.; Wang, Z.; Aydar, M. Artificial Intelligence in Precision Cardiovascular Medicine. J. Am. Coll. Cardiol. 2017, 691, 2657-2664. [CrossRef] [PubMed]

3. Lozano, R.; Naghavi, M.; Foreman, K.; Lim, S.; Shibuya, K.; Aboyans, V.; Abraham, J.; Adair, T.; Aggarwal, R.; Ahn, S.Y.; et al. Global and regional mortality from 235 causes of death for 20 age groups in 1990 and 2010: A systematic analysis for the Global Burden of Disease Study 2010. Lancet 2013, 380, 2095-2128. [CrossRef]

4. Benjamin, E.J.; Virani, S.S.; Callaway, C.W.; Chamberlain, A.M.; Chang, A.R.; Cheng, S.; Chiuve, S.E.; Cushman, M.; Delling, F.N.; Deo, R.; et al. Heart disease and stroke statistics-2018 update: A report from the American Heart Association. Circulation 2018, 137, e67-e492. [CrossRef] [PubMed]

5. Rowley, W.R.; Bezold, C.; Arikan, Y.; Byrne, E.; Krohe, S. Diabetes 2030: Insights from Yesterday, Today, and Future Trends. Popul. Health Manag. 2017, 20, 6-12. [CrossRef]

6. Leischik, R.; Dworrak, B.; Strauss, M.; Przybylek, B.; Dworrak, T.; Schöne, D.; Horlitz, M.; Mügge, A. Plasticity of Health. Ger. J. Med. 2016, 1, 1-17.

7. Sharma, V.; Sharma, V.; Shahjouei, S.; Li, J.; Chaudhary, D.; Khan, A.; Wolk, D.M.; Zand, R.; Abedi, V. At the Intersection of Gut Microbiome and Stroke: A Systematic Review of the Literature. Front. Neurol. 2021, 12, 729399. [CrossRef] [PubMed]

8. Lv, S.; Wang, Y.; Zhang, W.; Shang, H. Trimethylamine oxide: A potential target for heart failure therapy. Heart 2021. [CrossRef] [PubMed]

9. Collins, G.S.; Reitsma, J.B.; Altman, D.G.; Moons, K.G.M. Transparent reporting of a multivariable prediction model for individual prognosis or diagnosis (TRIPOD): The TRIPOD statement. BMJ 2015, 4, g7594. [CrossRef]

10. Weng, S.F.; Reps, J.; Kai, J.; Garibaldi, J.M.; Qureshi, N. Can machine-learning improve cardiovascular risk prediction using routine clinical data? PLOS ONE 2017, 12, e0174944. [CrossRef]

11. Commandeur, F.C.; Slomka, P.J.; Goeller, M.; Chen, X.; Cadet, S.; Razipour, A.; Gransar, H.; Cantu, S.; Miller, R.; Rozanski, A.; et al. Machine learning to predict the long-term risk of myocardial infarction and cardiac death based on clinical risk, coronary calcium, and epicardial adipose tissue: A prospective study. Cardiovasc. Res. 2019, 40, ehz747-0002. [CrossRef] [PubMed]

12. Ambale-Venkatesh, B.; Yang, X.; Wu, C.O.; Liu, K.; Hundley, W.G.; McClelland, R.; Gomes, A.S.; Folsom, A.R.; Shea, S.; Guallar, E.; et al. Cardiovascular Event Prediction by Machine Learning. Circ. Res. 2017, 121, 1092-1101. [CrossRef]

13. Kakadiaris, I.A.; Vrigkas, M.; Yen, A.A.; Kuznetsova, T.; Budoff, M.; Naghavi, M. Machine learning outperforms ACC/AHA CVD risk calculator in MESA. J. Am. Heart Assoc. 2018, 72, e009476. [CrossRef] [PubMed]

14. Li, H.; Cui, Y.; Zhu, Y.; Yan, H.; Xu, W. Association of high normal HbA1c and TSH levels with the risk of CHD: A 10-year cohort study and SVM analysis. Sci. Rep. 2017, 7, 45406. [CrossRef] [PubMed]

15. Eisenberg, E.; McElhinney, P.A.; Commandeur, F.; Chen, X.; Cadet, S.; Goeller, M.; Razipour, A.; Gransar, H.; Cantu, S.; Miller, R.J.; et al. Deep Learning-Based Quantification of Epicardial Adipose Tissue Volume and Attenuation Predicts Major Adverse Cardiovascular Events in Asymptomatic Subjects. Circ. Cardiovasc. Imaging 2020, 13, e009829. [CrossRef]

16. Samad, M.D.; Ulloa, A.; Wehner, G.J.; Jing, L.; Hartzel, D.; Good, C.W.; Williams, B.A.; Haggerty, C.M.; Fornwalt, B.K. Predicting Survival from Large Echocardiography and Electronic Health Record Datasets: Optimization with Machine Learning. JACC Cardiovasc. Imaging 2019, 12, 681-689. [CrossRef] [PubMed]

17. Johnson, K.M.; Johnson, H.E.; Zhao, Y.; Dowe, D.A.; Staib, L.H. Scoring of Coronary Artery Disease Characteristics on Coronary CT Angiograms by Using Machine Learning. Radiology 2019, 292, 354-362. [CrossRef] [PubMed]

18. Zhang, Y.; Zhou, Y.; Zhang, D.; Song, W. A Stroke Risk Detection: Improving Hybrid Feature Selection Method. J. Med. Internet Res. 2019, 21, e12437. [CrossRef] [PubMed]

19. Li, X.; Liu, H.; Du, X.; Zhang, P.; Hu, G.; Xie, G.; Guo, S.; Xu, M.; Xie, X. Integrated Machine Learning Approaches for Predicting Ischemic Stroke and Thromboembolism in Atrial Fibrillation. AMIA Annu. Symp. Proc. 2017, 2016, $799-807$.

20. Li, X.; Sun, Z.; Du, X.; Liu, H.; Hu, G.; Xie, G. Bootstrap-based Feature Selection to Balance Model Discrimination and Predictor Significance: A Study of Stroke Prediction in Atrial Fibrillation. AMIA Annu. Symp. 2017, 2017, 1130-1139.

21. Hung, C.-Y.; Lin, C.-H.; Lan, T.-H.; Peng, G.-S.; Lee, C.-C. Development of an intelligent decision support system for ischemic stroke risk assessment in a population-based electronic health record database. PLoS ONE 2019, 14, e0213007. [CrossRef] [PubMed]

22. Bild, D.E.; Bluemke, D.; Burke, G.L.; Detrano, R.; Roux, A.V.D.; Folsom, A.R.; Greenland, P.; Jacobs, D.R., Jr.; A Kronmal, R.; Liu, K.; et al. Multi-Ethnic Study of Atherosclerosis: Objectives and design. Am. J. Epidemiol. 2002, 156, 871-881. [CrossRef] [PubMed] 
23. Rozanski, A.; Gransar, H.; Shaw, L.J.; Kim, J.; Miranda-Peats, L.; Wong, N.D.; Rana, J.S.; Orakzai, R.; Hayes, S.W.; Friedman, J.D.; et al. Impact of coronary artery calcium scanning on coronary risk factors and downstream testing the EISNER (Early Identification of Subclinical Atherosclerosis by Noninvasive Imaging Research) prospective randomized trial. J. Am. Coll. Cardiol. 2011, 575, 1622-1632. [CrossRef] [PubMed]

24. Stuckey, T.D.; Gammon, R.S.; Goswami, R.; Depta, J.P.; Steuter, J.A.; Meine, F.J., 3rd; Roberts, M.C.; Singh, N.; Ramchandani, S.; Burton, T.; et al. Cardiac Phase Space Tomography: A novel method of assessing coronary artery disease utilizing machine learning. PLoS ONE 2018, 13, e0198603.

25. Dey, D.; Gaur, S.; Ovrehus, K.A.; Slomka, P.J.; Betancur, J.; Goeller, M.; Hell, M.M.; Gransar, H.; Berman, D.S.; Achenbach, S.; et al. Integrated prediction of lesion-specific ischaemia from quantitative coronary CT angiography using machine learning: $\mathrm{A}$ multicentre study. Eur. Radiol. 2018, 28, 2655-2664. [CrossRef] [PubMed]

26. Betancur, J.; Commandeur, F.; Motlagh, M.; Sharir, T.; Einstein, A.J.; Bokhari, S.; Fish, M.B.; Ruddy, T.D.; Kaufmann, P.; Sinusas, A.J.; et al. Deep Learning for Prediction of Obstructive Disease from Fast Myocardial Perfusion SPECT: A Multicenter Study. JACC Cardiovasc. Imaging 2018, 111, 1654-1663. [CrossRef] [PubMed]

27. Han, D.; Lee, J.H.; Rizvi, A.; Gransar, H.; Baskaran, L.; Schulman-Marcus, J.; Hartaigh, B.Ó.; Lin, F.Y.; Min, J.K. Incremental role of resting myocardial computed tomography perfusion for predicting physiologically significant coronary artery disease: A machine learning approach. J. Nucl. Cardiol. 2018, 25, 223-233. [CrossRef] [PubMed]

28. Sanchez-Martinez, S.; Duchateau, N.; Erdei, T.; Kunszt, G.; Aakhus, S.; Degiovanni, A.; Marino, P.; Carluccio, E.; Piella, G.; Fraser, A.G.; et al. Machine learning analysis of left ventricular function to characterize heart failure with preserved ejection fraction. Circ. Cardiovasc. Imaging 2018, 11, e007138. [CrossRef] [PubMed]

29. Ueda, D.; Yamamoto, A.; Nishimori, M.; Shimono, T.; Doishita, S.; Shimazaki, A.; Katayama, Y.; Fukumoto, S.; Choppin, A.; Shimahara, Y.; et al. Deep Learning for MR Angiography: Automated Detection of Cerebral Aneurysms. Radiology 2018, 290, 187-194. [CrossRef] [PubMed]

30. Cammarota, G.; Ianiro, G.; Ahern, A.; Carbone, C.; Temko, A.; Claesson, M.J.; Gasbarrini, A.; Tortora, G. Gut microbiome, big data and machine learning to promote precision medicine for cancer. Nat. Rev. Gastroenterol. Hepatol. 2020, 170, 635-648. [CrossRef] [PubMed]

31. Goldenberg, S.L.; Nir, G.; Salcudean, S.E. A new era: Artificial intelligence and machine learning in prostate cancer. Nat. Rev. Urol. 2019, 16, 391-403. [CrossRef] [PubMed]

32. Sinha, P.; Churpek, M.M.; Calfee, C.S. Machine Learning Classifier Models Can Identify Acute Respiratory Distress Syndrome Phenotypes Using Readily Available Clinical Data. Am. J. Respir. Crit. Care Med. 2020, 202, 996-1004. [CrossRef] [PubMed]

33. Tsoi, K.K.F.; Chan, N.B.; Yiu, K.K.L.; Poon, S.K.S.; Lin, B.; Ho, K. Machine Learning Clustering for Blood Pressure Variability Applied to Systolic Blood Pressure Intervention Trial (SPRINT) and the Hong Kong Community Cohort. Hypertension 2020, 76, 569-576. [CrossRef] [PubMed]

34. Fleuren, L.M.; Klausch, T.L.T.; Zwager, C.L.; Schoonmade, L.; Guo, T.; Roggeveen, L.F.; Swart, E.L.; Girbes, A.R.J.; Thoral, P.; Ercole, A.; et al. Machine learning for the prediction of sepsis: A systematic review and meta-analysis of diagnostic test accuracy. Intensive Care Med. 2020, 46, 383-400. [CrossRef] [PubMed]

35. Karlsson, L.O.; Nilsson, S.; Bång, M.; Nilsson, L.; Charitakis, E.; Janzon, M. A clinical decision support tool for improving adherence to guidelines on anticoagulant therapy in patients with atrial fibrillation at risk of stroke: A cluster-randomized trial in a Swedish primary care setting (the CDS-AF study). PLoS Med. 2018, 15, e1002528. [CrossRef] [PubMed]

36. Danchin, N.; Popovic, B.; Puymirat, E.; Goldstein, P.; Belle, L.; Cayla, G.; Roubille, F.; Lemesle, G.; Ferrières, J.; Schiele, F.; et al. Five-year outcomes following timely primary percutaneous intervention, late primary percutaneous intervention, or a pharmacoinvasive strategy in ST-segment elevation myocardial infarction: The FAST-MI programme. Eur. Heart J. 2020, 41, 858-866. [CrossRef] [PubMed]

37. Nicholson, B.D.; Dhindsa, H.S.; Roe, M.T.; Chen, A.Y.; Jollis, J.G.; Kontos, M.C. Relationship of the Distance Between Non-PCI Hospitals and Primary PCI Centers, Mode of Transport, and Reperfusion Time Among Ground and Air Interhospital Transfers Using NCDR's ACTION Registry-GWTG. Circ. Cardiovasc. Interv. 2014, 7, 797-805. [CrossRef]

38. Peretz, S.; Raphaeli, G.; Borenstein, N.; Leker, R.R.; Brauner, R.; Horev, A.; E Cohen, J.; Telman, G.; Halevi, H.; Tanne, D. Effect of time from onset to endovascular therapy on outcomes: The National Acute Stroke Israeli (NASIS)-REVASC registry. J. Neurointerv. Surg. 2020, 12, 13-18. [CrossRef] [PubMed]

39. Potter, B.J.; Matteau, A.; Mansour, S.; Naim, C.; Riahi, M.; Essiambre, R.; Montigny, M.; Sareault, I.; Gobeil, F. Sustained Performance of a 'Physicianless' System of Automated Prehospital STEMI Diagnosis and Catheterization Laboratory Activation. Can. J. Cardiol. 2017, 33, 148-154. [CrossRef] [PubMed]

40. Lyon, A.; Mincholé, A.; Martínez, J.; Laguna, P.; Rodriguez, B. Computational techniques for ECG analysis and interpretation in light of their contribution to medical advances. J. R. Soc. Interface 2018, 1538, 20170821. [CrossRef] [PubMed]

41. Goto, S.; Kimura, M.; Katsumata, Y.; Goto, S.; Kamatani, T.; Ichihara, G.; Ko, S.; Sasaki, J.; Fukuda, K.; Sano, M. Artificial intelligence to predict needs for urgent revascularization from 12-leads electrocardiography in emergency patients. PLoS ONE 2019, 14, e0210103.

42. Abedi, V.; Goyal, N.; Tsivgoulis, G.; Hosseinichimeh, N.; Hontecillas, R.; Bassaganya-Riera, J.; Elijovich, L.; Metter, J.E.; Alexandrov, A.W.; Liebeskind, D.S.; et al. Novel Screening Tool for Stroke Using Artificial Neural Network. Stroke 2017, 48, 1678-1681. [CrossRef] 
43. Sheth, S.A.; Lopez-Rivera, V.; Barman, A.; Grotta, J.C.; Yoo, A.J.; Lee, S.; Inam, M.E.; Savitz, S.I.; Giancardo, L. Machine Learning-Enabled Automated Determination of Acute Ischemic Core from Computed Tomography Angiography. Stroke 2019, 501, 3093-3100. [CrossRef] [PubMed]

44. Amukotuwa, S.A.; Straka, M.; Smith, H.; Chandra, R.; Dehkharghani, S.; Fischbein, N.J.; Bammer, R. Automated Detection of Intracranial Large Vessel Occlusions on Computed Tomography Angiography. Stroke 2019, 500, 2790-2798. [CrossRef] [PubMed]

45. Fhager, A.; Candefjord, S.; Elam, M.; Persson, M. 3D Simulations of Intracerebral Hemorrhage Detection Using Broadband Microwave Technology. Sensors 2019, 196, 3482. [CrossRef] [PubMed]

46. Kuo, W.; Häne, C.; Mukherjee, P.; Malik, J.; Yuh, E.L. Expert-level detection of acute intracranial hemorrhage on head computed tomography using deep learning. Proc. Natl. Acad. Sci. USA 2019, 1165, 22737-22745. [CrossRef] [PubMed]

47. Chang, P.D.; Kuoy, E.; Grinband, J.; Weinberg, B.D.; Thompson, M.; Homo, R.; Chen, J.; Abcede, H.; Shafie, M.; Sugrue, L.; et al. Hybrid 3D/2D Convolutional Neural Network for Hemorrhage Evaluation on Head CT. AJNR. Am. J. Neuroradiol. 2018, 39, 1609-1616. [CrossRef]

48. Ye, H.; Gao, F.; Yin, Y.; Guo, D.; Zhao, P.; Lu, Y.; Wang, X.; Bai, J.; Cao, K.; Song, Q.; et al. Precise diagnosis of intracranial hemorrhage and subtypes using a three-dimensional joint convolutional and recurrent neural network. Eur. Radiol. 2019, 291, 6191-6201. [CrossRef] [PubMed]

49. Cheon, S.; Kim, J.; Lim, J. The Use of Deep Learning to Predict Stroke Patient Mortality. Int. J. Environ. Res. Public Health 2019, 161, 1876. [CrossRef]

50. Abedi, V.; Avula, V.; Razavi, S.-M.; Shreya, B.; Chaudhary, D.; Shahjouei, S.; Wang, M.; Griessenauer, C.J.; Li, J.; Zand, R. Predicting short and long-term mortality after acute ischemic stroke using EHR. J. Neurol. Sci. 2021, 427, 117560. [CrossRef]

51. Stanciu, A.; Banciu, M.; Sadighi, A.; Marshall, K.A.; Holland, N.R.; Abedi, V.; Zand, R. A predictive analytics model for differentiating between transient ischemic attacks (TIA) and its mimics. BMC Med. Inform. Decis. Mak. 2020, 20, 112. [CrossRef] [PubMed]

52. alamir, M.A.; Noack, P.; Jang, K.H.; Moore, J.A.; Goldberg, R.; Poon, M. Computer-aided analysis of 64- and 320-slice coronary computed tomography angiography: A comparison with expert human interpretation. Int. J. Cardiovasc. Imaging 2018, 34, 1473-1483. [CrossRef]

53. Noh, Y.K.; Park, J.Y.; Choi, B.G.; Kim, K.E.; Rha, S.W. A Machine Learning-Based Approach for the Prediction of Acute Coronary Syndrome Requiring Revascularization. J. Med. Syst. 2019, 43, 253. [CrossRef] [PubMed]

54. Peter, R.; Korfiatis, P.; Blezek, D.; Beitia, A.O.; Stepan-Buksakowska, I.; Horinek, D.; Flemming, K.D.; Erickson, B.J. A quantitative symmetry-based analysis of hyperacute ischemic stroke lesions in noncontrast computed tomography. Med. Phys. 2017, 44, 192-199. [CrossRef] [PubMed]

55. Wu, O.; Winzeck, S.; Giese, A.-K.; Hancock, B.L.; Etherton, M.R.; Bouts, M.J.; Donahue, K.; Schirmer, M.D.; Irie, R.E.; Mocking, S.J.; et al. Big Data Approaches to Phenotyping Acute Ischemic Stroke Using Automated Lesion Segmentation of Multi-Center Magnetic Resonance Imaging Data. Stroke 2019, 50, 1734-1741. [CrossRef]

56. Liu, J.; Xu, H.; Chen, Q.; Zhang, T.; Sheng, W.; Huang, Q.; Song, J.; Huang, D.; Lan, L.; Li, Y.; et al. Prediction of hematoma expansion in spontaneous intracerebral hemorrhage using support vector machine. EBioMedicine 2019, 43, 454-459. [CrossRef] [PubMed]

57. Kasasbeh, A.S.; Christensen, S.; Parsons, M.W.; Campbell, B.; Albers, G.W.; Lansberg, M.G. Artificial Neural Network Computer Tomography Perfusion Prediction of Ischemic Core. Stroke 2019, 50, 1578-1581. [CrossRef] [PubMed]

58. Li, H.; Wu, T.T.; Yang, D.L.; Guo, Y.S.; Liu, P.C.; Chen, Y.; Xiao, L.P. Decision tree model for predicting in-hospital cardiac arrest among patients admitted with acute coronary syndrome. Clin. Cardiol. 2019, 421, 1087-1093. [CrossRef] [PubMed]

59. Alawieh, A.; Zaraket, F.; Alawieh, M.B.; Chatterjee, A.R.; Spiotta, A. Using machine learning to optimize selection of elderly patients for endovascular thrombectomy. J. Neurointerv. Surg. 2019, 11, 847-851. [CrossRef] [PubMed]

60. Ho, K.C.; Speier, W.; El-Saden, S.; Arnold, C.W. Classifying Acute Ischemic Stroke Onset Time using Deep Imaging Features. AMIA Annu. Symp. Proc. 2018, 2017, 892-901. [PubMed]

61. Abedi, V.; Khan, A.; Chaudhary, D.; Misra, D.; Avula, V.; Mathrawala, D.; Kraus, C.; Marshall, K.; Chaudhary, N.; Li, X.; et al. Using artificial intelligence for improving stroke diagnosis in emergency departments: A practical framework. Ther. Adv. Neurol. Disord. 2020, 13, 175628642093896. [CrossRef] [PubMed]

62. Ong, C.J.; Orfanoudaki, A.; Zhang, R.; Caprasse, F.P.M.; Hutch, M.; Ma, L.; Fard, D.; Balogun, O.; Miller, M.I.; Minnig, M.; et al. Machine learning and natural language processing methods to identify ischemic stroke, acuity and location from radiology reports. PLoS ONE 2020, 15, e0234908. [CrossRef] [PubMed]

63. Garg, R.; Oh, E.; Naidech, A.; Kording, K.; Prabhakaran, S. Automating Ischemic Stroke Subtype Classification Using Machine Learning and Natural Language Processing. J. Stroke Cerebrovasc. Dis. 2019, 28, 2045-2051. [CrossRef] [PubMed]

64. Adams, H.P., Jr.; Bendixen, B.H.; Kappelle, L.J.; Biller, J.; Love, B.B.; Gordon, D.L.; Marsh, E.E., 3rd. Classification of subtype of acute ischemic stroke. Definitions for use in a multicenter clinical trial. TOAST. Trial of Org 10172 in Acute Stroke Treatment. Stroke 1993, 24, 35-41. [CrossRef] [PubMed]

65. Keerthana, S.; Sathiyakumari, K. Brain Stroke Segmentation using Fuzzy C-Means Clustering. Int. J. Comput. Appl. 2016, 154, 26-30. [CrossRef]

66. Dey, D.; Slomka, P.J.; Leeson, P.; Comaniciu, D.; Shrestha, S.; Sengupta, P.P.; Marwick, T.H. Artificial Intelligence in Cardiovascular Imaging: JACC State-of-the-Art Review. J. Am. Coll. Cardiol. 2019, 154, $26-30$. 
67. Ernande, L.; Audureau, E.; Jellis, C.L.; Bergerot, C.; Henegar, C.; Sawaki, D.; Czibik, G.; Volpi, C.; Canoui-Poitrine, F.; Thibault, H.; et al. Clinical Implications of Echocardiographic Phenotypes of Patients with Diabetes Mellitus. J. Am. Coll. Cardiol. 2017, 704, 1704-1716. [CrossRef] [PubMed]

68. Katz, D.; Deo, R.C.; Aguilar, F.G.; Selvaraj, S.; Martinez, E.E.; Beussink-Nelson, M.L.; Kim, K.-Y.A.; Irvin, M.R.; Tiwari, H.; Rao, D.C.; et al. Phenomapping for the Identification of Hypertensive Patients with the Myocardial Substrate for Heart Failure with Preserved Ejection Fraction. J. Cardiovasc. Transl. Res. 2017, 10, 275-284. [CrossRef] [PubMed]

69. Lancaster, M.C.; Omar, A.M.S.; Narula, S.; Kulkarni, H.; Narula, J.; Sengupta, P.P. Phenotypic Clustering of Left Ventricular Diastolic Function Parameters. JACC Cardiovasc. Imaging 2019, 12, 1149-1161. [CrossRef] [PubMed]

70. Pecková, M.; Charvat, J.; Schuck, O.; Hill, M.; Svab, P.; Horackova, M. The Association between Left Ventricular Diastolic Function and a Mild-to-Moderate Decrease in Glomerular Filtration Rate in Patients with Type 2 Diabetes Mellitus. J. Int. Med. Res. 2011, 39, 2178-2186. [CrossRef] [PubMed]

71. Shah, S.J.; Katz, D.; Selvaraj, S.; Burke, M.A.; Yancy, C.W.; Gheorghiade, M.; Bonow, R.O.; Huang, C.-C.; Deo, R.C. Phenomapping for novel classification of heart failure with preserved ejection fraction. Circulation 2015, 131, 269-279. [CrossRef] [PubMed]

72. Zhao, J.; Zhang, Y.; Schlueter, D.J.; Wu, P.; Kerchberger, V.; Rosenbloom, S.T.; Wells, Q.S.; Feng, Q.; Denny, J.C.; Wei, W.-Q. Detecting time-evolving phenotypic topics via tensor factorization on electronic health records: Cardiovascular disease case study. J. Biomed. Inform. 2019, 98, 103270. [CrossRef] [PubMed]

73. Ahmad, T.; Pencina, M.J.; Schulte, P.J.; O’Brien, E.; Whellan, D.J.; Piña, I.L.; Kitzman, D.W.; Lee, K.L.; O'Connor, C.M.; Felker, G. Clinical implications of chronic heart failure phenotypes defined by cluster analysis. J. Am. Coll. Cardiol. 2014, 647, 1765-1774. [CrossRef] [PubMed]

74. Schulam, P.; Wigley, F.; Saria, S. Clustering longitudinal clinical marker trajectories from electronic health data: Applications to phenotyping and endotype discovery. In Proceedings of the National Conference on Artificial Intelligence, Austin, TX, USA, 25-30 January 2015.

75. Panahiazar, M.; Taslimitehrani, V.; Pereira, N.L.; Pathak, J. Using EHRs for Heart Failure Therapy Recommendation Using Multidimensional Patient Similarity Analytics. Stud. Health Technol. Inform. 2015, 210, 369-373. [PubMed]

76. Motwani, M.; Dey, D.; Berman, D.S.; Germano, G.; Achenbach, S.; Al-Mallah, M.; Andreini, D.; Budoff, M.J.; Cademartiri, F.; Callister, T.Q.; et al. Machine learning for prediction of all-cause mortality in patients with suspected coronary artery disease: A 5-year multicentre prospective registry analysis. Eur. Heart J. 2017, 38, 500-507. [CrossRef]

77. Cho, H.; Lee, J.-G.; Kang, S.-J.; Kim, W.-J.; Choi, S.-Y.; Ko, J.; Min, H.-S.; Choi, G.-H.; Kang, D.-Y.; Lee, P.H.; et al. AngiographyBased Machine Learning for Predicting Fractional Flow Reserve in Intermediate Coronary Artery Lesions. J. Am. Heart Assoc. 2019, 8, e011685. [CrossRef]

78. Zack, C.J.; Senecal, C.; Kinar, Y.; Metzger, Y.; Bar-Sinai, Y.; Widmer, R.J.; Lennon, R.; Singh, M.; Bell, M.R.; Lerman, A.; et al. Leveraging Machine Learning Techniques to Forecast Patient Prognosis After Percutaneous Coronary Intervention. JACC Cardiovasc. Interv. 2019, 124, 1304-1311. [CrossRef] [PubMed]

79. Mansoor, H.; Elgendy, I.Y.; Segal, R.; Bavry, A.A.; Bian, J. Risk prediction model for in-hospital mortality in women with ST-elevation myocardial infarction: A machine learning approach. Heart Lung 2017, 46, 405-411. [CrossRef]

80. Shouval, R.; Hadanny, A.; Shlomo, N.; Iakobishvili, Z.; Unger, R.; Zahger, D.; Alcalai, R.; Atar, S.; Gottlieb, S.; Matetzky, S.; et al. Machine learning for prediction of 30-day mortality after ST elevation myocardial infraction: An Acute Coronary Syndrome Israeli Survey data mining study. Int. J. Cardiol. 2017, 246, 7-13. [CrossRef]

81. Li, Y.-M.; Jiang, L.-C.; He, J.-J.; Jia, K.-Y.; Peng, Y.; Chen, M. Machine Learning to Predict the 1-Year Mortality Rate After Acute Anterior Myocardial Infarction in Chinese Patients. Ther. Clin. Risk Manag. 2020, 16, 1-6. [CrossRef] [PubMed]

82. Wallert, J.; Tomasoni, M.; Madison, G.; Held, C. Predicting two-year survival versus non-survival after first myocardial infarction using machine learning and Swedish national register data. BMC Med. Inform. Decis. Mak. 2017, 17, 99. [CrossRef] [PubMed]

83. Pieszko, K.; Hiczkiewicz, J.; Budzianowski, P.; Budzianowski, J.; Rzeźniczak, J.; Pieszko, K.; Burchardt, P. Predicting Long-Term Mortality after Acute Coronary Syndrome Using Machine Learning Techniques and Hematological Markers. Dis. Markers 2019, 2019, 9056402. [CrossRef] [PubMed]

84. Kwon, J.-M.; Jeon, K.-H.; Kim, H.M.; Kim, M.J.; Lim, S.; Kim, K.-H.; Song, P.S.; Park, J.; Choi, R.K.; Oh, B.-H. Deep-learning-based risk stratification for mortality of patients with acute myocardial infarction. PLoS ONE 2019, 140, e0224502. [CrossRef] [PubMed]

85. Duan, H.; Sun, Z.; Dong, W.; Huang, Z. Utilizing dynamic treatment information for MACE prediction of acute coronary syndrome. BMC Med. Inform. Decis. Mak. 2019, 19, 5. [CrossRef] [PubMed]

86. Ahmad, T.; Lund, L.H.; Rao, P.; Ghosh, R.; Warier, P.; Vaccaro, B.; Dahlström, U.; O'connor, C.M.; Felker, G.M.; Desai, N.R. Machine Learning Methods Improve Prognostication, Identify Clinically Distinct Phenotypes, and Detect Heterogeneity in Response to Therapy in a Large Cohort of Heart Failure Patients. J. Am. Heart Assoc. 2018, 7, e008081. [CrossRef] [PubMed]

87. Adler, E.D.; Voors, A.A.; Klein, L.; Macheret, F.; Braun, O.O.; Urey, M.A.; Zhu, W.; Sama, I.; Tadel, M.; Campagnari, C.; et al. Improving risk prediction in heart failure using machine learning. Eur. J. Heart Fail. 2019, 22, 139-147. [CrossRef] [PubMed]

88. Kwon, J.M.; Kim, K.H.; Jeon, K.H.; Lee, S.E.; Lee, H.Y.; Cho, H.J.; Choi, J.O.; Jeon, E.S.; Kim, M.S.; Kim, J.J.; et al. Artificial intelligence algorithm for predicting mortality of patients with acute heart failure. PLoS ONE 2019, 14, e0219302. [CrossRef] [PubMed] 
89. Kwon, J.-M.; Kim, K.-H.; Jeon, K.-H.; Lee, S.E.; Lee, H.-Y.; Cho, H.-J.; Choi, J.O.; Jeon, E.-S.; Kim, M.-S.; Kim, J.-J.; et al. Machine Learning of Three-dimensional Right Ventricular Motion Enables Outcome Prediction in Pulmonary Hypertension: A Cardiac MR Imaging Study. Radiology 2017, 283, 381-390.

90. Anne, N.; Bo, H.M.; Anna, T.; Kim, M. Prediction of Tissue Outcome and Assessment of Treatment Effect in Acute Ischemic Stroke Using Deep Learning. Stroke 2018, 49, 1394-1401.

91. Heo, J.; Yoon, J.G.; Park, H.; Kim, Y.D.; Nam, H.S.; Heo, J.H. Machine Learning-Based Model for Prediction of Outcomes in Acute Stroke. Stroke 2019, 50, 1263-1265. [CrossRef] [PubMed]

92. Xie, Y.; Jiang, B.; Gong, E.; Li, Y.; Zhu, G.; Michel, P.; Wintermark, M.; Zaharchuk, G. Use of gradient boosting machine learning to predict patient outcome in acute ischemic stroke on the basis of imaging, demographic, and clinical information. Am. J. Roentgenol. 2019, 22, 44-51. [CrossRef] [PubMed]

93. Xu, Y.; Yang, X.; Huang, H.; Peng, C.; Ge, Y.; Wu, H.; Wang, J.; Xiong, G.; Yi, Y. Extreme Gradient Boosting Model Has a Better Performance in Predicting the Risk of 90-Day Readmissions in Patients with Ischaemic Stroke. J. Stroke Cerebrovasc. Dis. 2019, 282, 104441. [CrossRef]

94. Chan, K.L.; Leng, X.; Zhang, W.; Dong, W.; Qiu, Q.; Yang, J.; Soo, Y.; Wong, K.S.; Leung, T.W.; Liu, J. Early Identification of High-Risk TIA or Minor Stroke Using Artificial Neural Network. Front. Neurol. 2019, 10, 171. [CrossRef] [PubMed]

95. Van Os, H.J.A.; Ramos, L.A.; Hilbert, A.; van Leeuwen, M.; Van Walderveen, M.A.A.; Kruyt, N.D.; Dippel, D.W.J.; Steyerberg, E.W.; Van Der Schaaf, I.C.; Lingsma, H.F.; et al. Predicting outcome of endovascular treatment for acute ischemic stroke: Potential value of machine learning algorithms. Front. Neurol. 2018, 9, 784. [CrossRef] [PubMed]

96. Park, S.; Megjhani, M.; Frey, H.-P.; Grave, E.; Wiggins, C.; Terilli, K.L.; Roh, D.J.; Velázquez, Á.; Agarwal, S.; Connolly, E.S.; et al. Predicting delayed cerebral ischemia after subarachnoid hemorrhage using physiological time series data. J. Clin. Monit. Comput. 2019, 33, 95-105. [CrossRef] [PubMed]

97. Broderick, J.; Adeoye, O.; Elm, J. Evolution of the Modified Rankin Scale and Its Use in Future Stroke Trials. Stroke 2017, 48, 2007-2012. [CrossRef] [PubMed]

98. Caraballo, C.; Desai, N.R.; Mulder, H.; Alhanti, B.; Wilson, F.P.; Fiuzat, M.; Felker, G.M.; Piña, I.L.; O'Connor, C.M.; Lindenfeld, J.; et al. Clinical Implications of the New York Heart Association Classification. J. Am. Heart Assoc. 2019, 83, e014240. [CrossRef]

99. Cikes, M.; Sanchez-Martinez, S.; Claggett, B.; Duchateau, N.; Piella, G.; Butakoff, C.; Pouleur, A.C.; Knappe, D.; Biering-Sørensen, T.; Kutyifa, V.; et al. Machine learning-based phenogrouping in heart failure to identify responders to cardiac resynchronization therapy. Eur. J. Heart Fail. 2019, 21, 74-85. [CrossRef] [PubMed]

100. Lin, W.-Y.; Chen, C.-H.; Tseng, Y.-J.; Tsai, Y.-T.; Chang, C.-Y.; Wang, H.-Y.; Chen, C.-K. Predicting post-stroke activities of daily living through a machine learning-based approach on initiating rehabilitation. Int. J. Med. Inform. 2018, 111, 159-164. [CrossRef] [PubMed]

101. Shields, G.E.; Wells, A.; Doherty, P.; Heagerty, A.; Buck, D.; Davies, L.M. Cost-effectiveness of cardiac rehabilitation: A systematic review. Heart 2018, 1047, 1403-1410. [CrossRef] [PubMed]

102. Rajsic, S.; Gothe, H.; Borba, H.H.; Sroczynski, G.; Vujicic, J.; Toell, T.; Siebert, U. Economic burden of stroke: A systematic review on post-stroke care. Eur. J. Health Econ. 2019, 20, 107-134. [CrossRef]

103. Goetz, L.H.; Schork, N.J. Personalized medicine: Motivation, challenges, and progress. Fertil. Steril. 2018, 109, 952-963. [CrossRef] [PubMed]

104. Feeny, A.K.; Rickard, J.; Patel, D.; Toro, S.; Trulock, K.M.; Park, C.J.; LaBarbera, M.A.; Varma, N.; Niebauer, M.J.; Sinha, S.; et al. Machine Learning Prediction of Response to Cardiac Resynchronization Therapy: Improvement Versus Current Guidelines. Circ. Arrhythm. Electrophysiol. 2019, 12, e007316. [CrossRef] [PubMed]

105. Hu, S.-Y.; Santus, E.; Forsyth, A.W.; Malhotra, D.; Haimson, J.; Chatterjee, N.A.; Kramer, D.B.; Barzilay, R.; Tulsky, J.A.; Lindvall, C. Can machine learning improve patient selection for cardiac resynchronization therapy? PLoS ONE 2019, 140, e0222397. [CrossRef]

106. Kalscheur, M.M.; Kipp, R.T.; Tattersall, M.C.; Mei, C.; Buhr, K.A.; DeMets, D.L.; Field, M.E.; Eckhardt, L.L.; Page, C.D. Machine Learning Algorithm Predicts Cardiac Resynchronization Therapy Outcomes: Lessons from the COMPANION Trial. Circ. Arrhythm. Electrophysiol. 2018, 11, e005499. [CrossRef] [PubMed]

107. Isma'Eel, H.A.; Sakr, G.E.; Serhan, M.; Lamaa, N.; Hakim, A.; Cremer, P.C.; Jaber, W.A.; Garabedian, T.; Elhajj, I.; Abchee, A.B. Artificial neural network-based model enhances risk stratification and reduces non-invasive cardiac stress imaging compared to Diamond-Forrester and Morise risk assessment models: A prospective study. J. Nucl. Cardiol. Off. Publ. Am. Soc. Nucl. Cardiol. 2018, 25, 1601-1609. [CrossRef] [PubMed]

108. Stolarz-Skrzypek, K.; Kuznetsova, T.; Thijs, L.; Tikhonoff, V.; Seidlerová, J.; Richart, T.; Jin, Y.; Olszanecka, A.; Malyutina, S.; Casiglia, E.; et al. Fatal and nonfatal outcomes, incidence of hypertension, and blood pressure changes in relation to urinary sodium excretion. JAMA 2011, 3057, 1777-1785. [CrossRef]

109. Ayatollahi, H.; Gholamhosseini, L.; Salehi, M. Predicting coronary artery disease: A comparison between two data mining algorithms. BMC Public Health 2019, 19, 448. [CrossRef] [PubMed]

110. Min, J.K.; Dunning, A.; Lin, F.Y.; Achenbach, S.; Al-Mallah, M.H.; Berman, D.S.; Budoff, M.J.; Cademartiri, F.; Callister, T.Q.; Chang, H.-J.; et al. Rationale and design of the CONFIRM (COronary CT Angiography EvaluatioN for Clinical Outcomes: An InteRnational Multicenter) Registry. J. Cardiovasc. Comput. Tomogr. 2011, 5, 84-92. [CrossRef] [PubMed] 
111. Bhuva, A.N.; Bai, W.; Lau, C.; Davies, R.H.; Ye, Y.; Bulluck, H.; McAlindon, E.; Culotta, V.; Swoboda, P.; Captur, G.; et al. A Multicenter, Scan-Rescan, Human and Machine Learning CMR Study to Test Generalizability and Precision in Imaging Biomarker Analysis. Circ. Cardiovasc. Imaging 2019, 120, e009214. [CrossRef] [PubMed]

112. Hearn, J.; Ross, H.J.; Mueller, B.; Fan, C.-P.; Crowdy, E.; Duhamel, J.; Walker, M.; Alba, A.C.; Manlhiot, C. Neural Networks for Prognostication of Patients with Heart Failure. Circ. Heart Fail. 2018, 11, e005193. [CrossRef]

113. Jamthikar, A.; Gupta, D.; Khanna, N.N.; Saba, L.; Araki, T.; Viskovic, K.; Suri, H.S.; Gupta, A.; Mavrogeni, S.; Turk, M.; et al. A low-cost machine learning-based cardiovascular/stroke risk assessment system: Integration of conventional factors with image phenotypes. Cardiovasc. Diagn. Ther. 2019, 9, 420-430. [CrossRef] [PubMed]

114. Bristow, M.R.; Saxon, L.A.; Boehmer, J.; Krueger, S.; Kass, D.A.; De Marco, T.; Carson, P.; Dicarlo, L.; DeMets, D.; White, B.G.; et al. Cardiac-Resynchronization Therapy for the Prevention of Heart-Failure Events. N. Engl. J. Med. 2009, 3614, $1329-1338$.

115. Bristow, M.R.; Saxon, L.A.; Boehmer, J.; Krueger, S.; Kass, D.A.; De Marco, T.; Carson, P.; Dicarlo, L.; DeMets, D.; White, B.G.; et al. Cardiac-resynchronization therapy with or without an implantable defibrillator in advanced chronic heart failure. N. Engl. J. Med. 2004, 3501, 2140-2150. [CrossRef] [PubMed]

116. Nørgaard, B.L.; Leipsic, J.; Gaur, S.; Seneviratne, S.; Ko, B.S.; Ito, H.; Jensen, J.M.; Mauri, L.; De Bruyne, B.; Bezerra, H.; et al. Diagnostic Performance of Noninvasive Fractional Flow Reserve Derived from Coronary Computed Tomography Angiography in Suspected Coronary Artery Disease. J. Am. Coll. Cardiol 2014, 632, 1145-1155. [CrossRef]

117. van Rosendael, A.R.; Maliakal, G.; Kolli, K.K.; Beecy, A.; Al'Aref, S.J.; Dwivedi, A.; Singh, G.; Panday, M.; Kumar, A.; Ma, X.; et al. Maximization of the usage of coronary CTA derived plaque information using a machine learning based algorithm to improve risk stratification; insights from the CONFIRM registry. J. Cardiovasc. Comput. Tomogr. 2018, 12, 204-209. [CrossRef] [PubMed]

118. Coenen, A.; Kim, Y.H.; Kruk, M.; Tesche, C.; De Geer, J.; Kurata, A.; Lubbers, M.L.; Daemen, J.; Itu, L.; Rapaka, S.; et al. Diagnostic Accuracy of a Machine-Learning Approach to Coronary Computed Tomographic Angiography-Based Fractional Flow Reserve. Circ. Cardiovasc. Imaging 2018, 11, e007217. [CrossRef] [PubMed]

119. Min, J.K.; Leipsic, J.; Pencina, M.J.; Berman, D.S.; Koo, B.-K.; Van Mieghem, C.; Erglis, A.; Lin, F.Y.; Dunning, A.M.; Apruzzese, P.; et al. Diagnostic accuracy of fractional flow reserve from anatomic CT angiography. JAMA 2012, 3082, 1237-1245. [CrossRef]

120. Lin, J.; Jiang, A.; Ling, M.; Mo, Y.; Li, M.; Zhao, J. Prediction of neurologic deterioration based on support vector machine algorithms and serum osmolarity equations. Brain Behav. 2018, 8, e01023. [CrossRef] [PubMed]

121. Harrer, S.; Shah, P.; Antony, B.; Hu, J. Artificial Intelligence for Clinical Trial Design. Trends Pharmacol. Sci. 2019, 40, 577-591. [CrossRef]

122. Pappalardo, F.; Russo, G.; Tshinanu, F.M.; Viceconti, M. In silico clinical trials: Concepts and early adoptions. Brief. Bioinform. 2018, 20, 1699-1708. [CrossRef]

123. Abedi, V.; Lu, P.; Hontecillas, R.; Verma, M.; Vess, G.; Philipson, C.; Carbo, A.; Leber, A.; Juni, N.; Hoops, S.; et al. Phase III Placebo-Controlled, Randomized Clinical Trial with Synthetic Crohn's Disease Patients to Evaluate Treatment Response. Emerg. Trends Appl. Infrastruct. Comput. Biol. Bioinform. Syst. Biol. 2015, 2, 169.

124. Li, N.Y.K.; Verdolini, K.; Clermont, G.; Mi, Q.; Rubinstein, E.N.; Hebda, P.A.; Vodovotz, Y. A patient-specific in silico model of inflammation and healing tested in acute vocal fold injury. PLOS ONE 2008, 3, e2789. [CrossRef]

125. Valerio, L.G. Application of advanced in silico methods for predictive modeling and information integration. Expert Opin. Drug Metab. Toxicol. 2012, 8, 395-398. [CrossRef] [PubMed]

126. Filipiak-Strzecka, D.; Kasprzak, J.D.; Szymczyk, E.; Wejner-Mik, P.; Lipiec, P. Bedside screening with the use of pocket-size imaging device can be useful for ruling out carotid artery stenosis in patients scheduled for cardiac surgery. Echocardiography 2017, 34, 716-722. [CrossRef] [PubMed]

127. Osheroff, J.A.; Teich, J.M.; Middleton, B.; Steen, E.B.; Wright, A.; Detmer, D.E. A Roadmap for National Action on Clinical Decision Support. J. Am. Med. Inform. Assoc. 2007, 14, 141-145. [CrossRef] [PubMed]

128. Varonen, H.; Kortteisto, T.; Kaila, M. What may help or hinder the implementation of computerized decision support systems (CDSSs): A focus group study with physicians. Fam. Pract. 2008, 25, 162-167. [CrossRef]

129. Bouaud, J.; Spano, J.-P.; Lefranc, J.-P.; Cojean-Zelek, I.; Blaszka-Jaulerry, B.; Zelek, L.; Durieux, A.; Tournigand, C.; Rousseau, A.; Vandenbussche, P.-Y.; et al. Physicians' Attitudes Towards the Advice of a Guideline-Based Decision Support System: A Case Study with OncoDoc2 in the Management of Breast Cancer Patients. Stud. Health Technol. Inform. 2015, 216, 264-269. [PubMed]

130. Van Der Sijs, H.; Mulder, A.; van Gelder, T.; Aarts, J.; Berg, M.; Vulto, A. Drug safety alert generation and overriding in a large Dutch university medical centre. Pharmacoepidemiol. Drug Saf. 2009, 180, 941-947. [CrossRef] [PubMed]

131. Van Der Sijs, H.; Aarts, J.; Vulto, A.; Berg, M. Overriding of drug safety alerts in computerized physician order entry. J. Am. Med. Inform. Assoc. 2006, 13, 138-147. [CrossRef]

132. Bergman, L.G.; Fors, U.G.H. Computer-aided DSM-IV-diagnostics-Acceptance, use and perceived usefulness in relation to users' learning styles. BMC Med. Inform. Decis. Mak. 2005, 5, 1. [CrossRef]

133. Curry, L.; Reed, M.H. Electronic decision support for diagnostic imaging in a primary care setting. J. Am. Med. Inform. Assoc. 2011, 18, 267-270. [CrossRef] [PubMed]

134. Zheng, K.; Padman, R.; Johnson, M.; Diamond, H.S. Understanding technology adoption in clinical care: Clinician adoption behavior of a point-of-care reminder system. Int. J. Med. Inform. 2005, 74, 535-543. [CrossRef]

135. Rousseau, N.; McColl, E.; Newton, J.; Grimshaw, J.; Eccles, M. Practice based, longitudinal, qualitative interview study of computerised evidence based guidelines in primary care. Br. Med. J. 2003, 326, 314-318. [CrossRef] 
136. Johnson, M.; Zheng, K.; Padman, R. Modeling the longitudinality of user acceptance of technology with an evidence-adaptive clinical decision support system. Decis. Support Syst. 2014, 57, 444-453. [CrossRef]

137. Sousa, V.E.C.; Lopez, K.D.; Febretti, A.; Stifter, J.; Yao, Y.; Johnson, A.; Wilkie, D.J.; Keenan, G.M. Use of simulation to study nurses' acceptance and nonacceptance of clinical decision support suggestions. CIN Comput. Inform. Nurs. 2015, 330, 465-472. [CrossRef] [PubMed]

138. Terraz, O.; Wietlisbach, V.; Jeannot, J.-G.; Burnand, B.; Froehlich, F.; Gonvers, J.-J.; Harris, J.K.; Vader, J.-P. The EPAGE internet guideline as a decision support tool for determining the appropriateness of colonoscopy. Digestion 2005, 71, 72-77. [CrossRef] [PubMed]

139. Gadd, C.S.; Baskaran, P.; Lobach, D.F. Identification of design features to enhance utilization and acceptance of systems for Internet-based decision support at the point of care. Proc. AMIA Symp. 1998, 91-95. Available online: https://www.ncbi.nlm.nih. gov/pmc/articles/PMC2232383/ (accessed on 15 November 2021).

140. Khalifa, M. Clinical Decision Support: Strategies for Success. Procedia Comput. Sci. 2014, 37, 422-427. [CrossRef]

141. McCoy, A.B.; Thomas, E.J.; Krousel-Wood, M.; Sittig, D.F. Clinical decision support alert appropriateness: A review and proposal for improvement. Ochsner J. 2014, 14, 195-202.

142. Aakre, C.A.; Dziadzko, M.A.; Herasevich, V. Towards automated calculation of evidence-based clinical scores. World J. Methodol. 2017, 7, 16. [CrossRef]

143. Khairat, S.; Marc, D.; Crosby, W.; al Sanousi, A. Reasons for Physicians Not Adopting Clinical Decision Support Systems: Critical Analysis. JMIR Med. Inform. 2018, 6, e24. [CrossRef] [PubMed]

144. Kanstrup, A.M.; Christiansen, M.B.; Nøhr, C. Four principles for user interface design of computerised clinical decision support systems. Stud. Health Technol. Inform. 2011, 166, 65-73.

145. Venkatesh, V.; Morris, M.G.; Davis, G.B.; Davis, F.D. User acceptance of information technology: Toward a unified view. MIS Q. Manag. Inf. Syst. 2003, 27, 425-478. [CrossRef]

146. Peleg, M.; Shachak, A.; Wang, D.; Karnieli, E. Using multi-perspective methodologies to study users' interactions with the prototype front end of a guideline-based decision support system for diabetic foot care. Int. J. Med. Inform. 2009, 78, 482-493. [CrossRef]

147. Rudin, R.S.; Fischer, S.H.; Shi, Y.; Shekelle, P.; Amill-Rosario, A.; Damberg, C.L. Trends in the Use of Clinical Decision Support by Health System-Affiliated Ambulatory Clinics in the United States, 2014-2016. Am. J. Acc. Care 2019, 7, 4-10.

148. Parikh, R.B.; Teeple, S.; Navathe, A.S. Addressing Bias in Artificial Intelligence in Health Care. JAMA 2019, 322, $2377-2378$. [CrossRef] [PubMed]

149. Mitchell, J.; Probst, J.; Brock-Martin, A.; Bennett, K.; Glover, S.; Hardin, J. Association between clinical decision support system use and rural quality disparities in the treatment of pneumonia. J. Rural Health 2014, 30, 186-195. [CrossRef] [PubMed]

150. Samal, L.; Lipsitz, S.R.; Hicks, L.R.S. Impact of electronic health records on racial and ethnic disparities in blood pressure control at US primary care visits. Arch. Intern. Med. 2012, 172, 75-76. [CrossRef]

151. Sintchenko, V.; Coiera, E.; Iredell, J.R.; Gilbert, G.L. Comparative Impact of Guidelines, Clinical Data, and Decision Support on Prescribing Decisions: An Interactive Web Experiment with Simulated Cases. J. Am. Med. Inform. Assoc. 2004, 11, 71-77. [CrossRef] [PubMed]

152. Gao, Y.; Cui, Y. Deep transfer learning for reducing health care disparities arising from biomedical data inequality. Nat. Commun. 2020, 11, 5131. [CrossRef]

153. Cirillo, D.; Catuara-Solarz, S.; Morey, C.; Guney, E.; Subirats, L.; Mellino, S.; Gigante, A.; Valencia, A.; Rementeria, M.J.; Chadha, A.S.; et al. Sex and gender differences and biases in artificial intelligence for biomedicine and healthcare. NPJ Digit. Med. 2020, 3, 81. [CrossRef] [PubMed]

154. Abedi, V.; Li, J.; Shivakumar, M.K.; Avula, V.; Chaudhary, D.P.; Shellenberger, M.J.; Khara, H.S.; Zhang, Y.; Lee, M.T.M.; Wolk, D.M.; et al. Increasing the Density of Laboratory Measures for Machine Learning Applications. J. Clin. Med. 2020, 10, 103. [CrossRef] [PubMed]

155. Li, J.; Yan, X.S.; Chaudhary, D.; Avula, V.; Mudiganti, S.; Husby, H.; Shahjouei, S.; Afshar, A.; Stewart, W.F.; Yeasin, M.; et al. Imputation of missing values for electronic health record laboratory data. NPJ Digit. Med. 2021, 4, 147. [CrossRef] [PubMed] 